\title{
Expectations and Investment
}

\author{
Nicola Gennaioli, Universita' Bocconi \\ Yueran Ma, Harvard University \\ Andrei Shleifer, Harvard University and NBER
}

\begin{abstract}
Using micro data from Duke University quarterly survey of Chief Financial Officers, we show that corporate investment plans as well as actual investment are well explained by CFOs' expectations of earnings growth. The information in expectations data is not subsumed by traditional variables, such as Tobin's $Q$ or discount rates. We also show that errors in $\mathrm{CFO}$ expectations of earnings growth are predictable from past earnings and other data, pointing to extrapolative structure of expectations and suggesting that expectations may not be rational. This evidence, like earlier findings in finance, points to the usefulness of data on actual expectations for understanding economic behavior.
\end{abstract}

\section{Introduction}

One of the basic principles of economics in general, and macroeconomics in particular, is that expectations influence decisions. In line with this principle, the use of survey-based expectations data has been the mainstay of macroeconomic analysis since the 1940s, analyzing variables such as railroad shippers' forecasts. The NBER published several volumes on data of this kind, such as The Quality and Economic Significance of Anticipations Data (1960), showing that forecasts help to explain real decisions by firms, including investment and production.

The use of expectations data took a nosedive following the Rational Expectations Revolution. Under rational expectations, the model itself dictates what expectations rational agents should hold to be consistent with the model (Muth 1961), so anticipations data are redundant. 
Economists also became skeptical about the quality of expectations data; in fact, this skepticism predates rational expectations (Manski 2004). According to Prescott $(1977,30)$, "Like utility, expectations are not observed, and surveys cannot be used to test the rational expectations hypothesis" (emphasis his). In finance, as in macroeconomics, the Efficient Markets Hypothesis implies that expectations of asset returns are predicted by the model (Campbell and Cochrane 1999; Lettau and Ludvigson 2001), so expectations data are not commonly used.

In our view, the marginalization of research on survey expectations deprives economists of extremely valuable information. Whether or not survey expectations predict behavior is an empirical question. The rational expectations assumption should not be taken for granted, but rather confronted with actual expectations data, imperfect as they are. Today, we have theoretical models that do not rely on the rational expectations assumption and make testable predictions, as well as expectations data to compare alternative models. Indeed, Manski (2004) argues forcefully and convincingly that expectations data are necessary to distinguish alternative models in economics.

As an illustration, take the case of finance, where data on expectations of asset returns have been rejected as uninformative (Cochrane 2011). Yet there is mounting evidence that expectations are highly consistent across different surveys of different types of investors, that they have a fairly clear extrapolative structure, that they predict investor behavior, and that they are useful in predicting returns (Greenwood and Shleifer 2014). Most important, expectations of returns obtained from surveys are negatively correlated with measures of expected returns obtained from rational expectations models. The trouble seems to be with conventional rational expectations models of asset prices, not with expectations data.

The message we take from this discussion is that expectations data can be used to address two questions: (a) Do expectations affect behavior? and (b) Are expectations rational? The questions are related. If expectations do not affect behavior, it matters little whether they are rational or not. If, however, expectations do affect behavior, the question of their rationality becomes quite relevant, since it allows us to consider alternative models of belief formation underlying economic decisions.

In this paper, we try to answer these questions for the case of corporate investment. We use new data assembled by John Graham and Campbell Harvey at Duke University to examine expectations formed by Chief Financial Officers (CFOs) of large US corporations and their relationship to investment plans and actual investment of these firms. The Duke data are based on quarterly surveys of CFOs which, among other 
things, collect information on earnings growth expectations and investment plans. We match these data with Compustat to get information on actual investment and other accounting variables. We also consider earnings forecasts made by Wall Street financial analysts regarding individual firms, which happen to be highly correlated with CFO forecasts.

To organize our discussion, we present a simple $q$-theory-based model of investment, but one relying on actual expectations rather than stock market data. We then conduct a number of empirical tests suggested by the model of the relationship between earnings growth expectations and investment growth, both in the aggregate and firmlevel data. The results suggest that expectations are statistically and substantively important predictors of both planned and actual investment, and have explanatory power beyond traditional variables such as market-based proxies of Tobin's $q$, discount rates, measures of financial constraints, or uncertainty. We then conduct a number of empirical tests on the rationality of expectations. In our data, expectations do not appear to be rational in the sense that-both in the aggregate and at the level of individual firms - expectational errors are consistently predictable from highly relevant publicly available information, such as past profitability. Some evidence points to the extrapolative structure of earnings expectations, similar to the evidence from finance.

Our paper is related to several very large strands of research. Most clearly, it is related to a large literature on determinants of investment, such as Barro (1990), Hayashi (1982), Fazzari, Hubbard, and Petersen (1988), Morck et al. (1990), Lamont (2000), and many others. Eisner (1978) is the classic study of the effects of sales anticipations on investment, with results broadly similar to ours. Four further papers are closely related to our work. Cummins, Hassett, and Oliner (2006) replace the traditional market-based Tobin's $q$ used in investment equations by $q$ computed using analyst expectations data, and find that the fit of the equation is much better. Guiso, Pistaferri, and Suryanarayanan (2006) use direct expectations data on Italian firms to study the relationship between expectations, investment plans, and actual investment. Arif and Lee (2014) use accounting data to show that high aggregate investment precedes earnings disappointments, and argue that fluctuations in investor sentiment account for the evidence. Greenwood and Hanson (2015) specifically study the shipping industry, and find evidence of boom-bust cycles driven by volatile (and incorrect) expectations and investment that follows them.

Our paper is also related to research on expectations in macroeconomics. A large literature studies inflation expectations and their rationality (e.g., Figlewski and Wachtel 1981; Zarnowitz 1985; Keane and Runkle 1990; Ang, 
Bakaert, and Wei 2007; Monti 2010; Del Negro and Eusepi 2011; Coibion and Gorodnichenko 2012, 2015; Smets, Warne, and Wouters 2014). Souleles (2004) finds that consumer expectations are biased and inefficient, yet are strong predictors of household spending. Burnside, Eichenbaum, and Rebelo (2015) present a model of "social dynamics" in beliefs about home prices and match the model to survey expectations data. Fuhrer (2015) shows that survey expectations improve the performance of dynamic stochastic general equilibrium (DSGE) models. Some research suggests that analyst expectations of corporate profits are rational at very short horizons (Keane and Runkle 1998), although the overwhelming majority of studies reject rationality of analyst forecasts (De Bondt and Thaler 1990; Abarbanell 1991; La Porta 1996; Liu and Su 2005; Hribar and McInnis 2012). There is also a literature on expectations shocks in macroeconomics, which generally maintains the assumption of rational expectations (Lorenzoni 2009; Angeletos and La'O 2010; Levchenko and Pandalai-Nayar 2015).

Perhaps most closely related to our work is research in behavioral finance, where biases in expectations have been examined for many years (e.g., Cutler, Poterba, and Summers 1990; De Long et al. 1990). Some of the recent papers include Amromin and Sharpe (2014), Bacchetta, Mertens, and Wincoop (2009), Hirshleifer, Li, and Yu (2015), and Greenwood and Shleifer (2014), to which we return later. Several of these papers find that investor expectations are extrapolative. In the bond market, Piazzesi, Salomao, and Schneider (2015) use data on interest-rate forecasts and also find substantial deviations from rationality. Vissing-Jorgensen (2004) and Fuster, Hebert, and Laibson (2012) are two recent Macroeconomics Annual papers that also address expectations formation and rationality.

In the next section, we briefly summarize some of the evidence on the relationship between investor expectations and asset prices, and address some of the criticisms of expectations data. Section III describes our data. Section IV presents a simple $q$-theory model of expectations and investment that organizes our empirical work. Section $V$ follows with the basic empirical results on expectations and investment. Section VI examines the structure of expectations. Section VII concludes with a brief discussion of implications of the evidence for macroeconomics.

\section{Recent Research on Expectations and Asset Prices in Finance}

Before turning to our main results on investment, we briefly summarize recent research on expectations and stock market returns, which illustrates the usefulness of expectations data. In recent models with 
time-varying expected returns (e.g., Campbell and Cochrane 1999; Lettau and Ludvigson 2001), expected returns (ER) are given by required returns, which in turn depend on consumption: investors require higher returns when consumption is low (relative to some benchmark), and lower returns when consumption is high. This research does not generally use data on expectations. Rather, it adopts a rational expectations approach in which ERs are determined by the model itself, so the ER is inferred from the joint distribution of consumption and realized returns.

As discussed in the introduction, recent work has started to use actual expectations data. For our purposes, the most relevant paper is Greenwood and Shleifer (2014). They use data on expectations of returns from six different surveys of investors, including a Gallup survey, investor newsletters, and the survey of CFOs of large corporations that we use in the current paper. The paper reports four main findings relevant to our analysis, which we summarize in tables 1 and 2.

First, expectations of aggregate stock returns are highly correlated across investor surveys, despite the fact that different data sets survey different investors and ask somewhat different questions (see table 1). These measured expectations are also highly positively correlated with equity mutual fund inflows. Survey expectations are thus hardly misleading or uninformative: Why would they otherwise be strongly correlated across groups, across questions, and with fund flows?

Second, return expectations appear to be extrapolative: they are high after a period of high market returns, and low after a period of low market returns (see table 1 and figure 1).

Third, and critically, expectations of returns are strongly negatively correlated with model-based measures of the ER (see again table 1). Put simply, when investors expect returns to be high, models predict that the ER is low. A plausible interpretation of this finding is that model-based ER does not actually capture expectations.

Fourth, when expectations of returns are high and the ER is low, actual returns going forward are low (see table 2). To us, this piece of evidence points to the interpretation, dating back to Campbell and Shiller (1987, 1988), that high market valuations and consumption reflect overvaluation and excessive investor optimism (as directly measured by expectations), and portend reversion going forward. Model-based ER, in other words, does not measure expectations, but rather proxies for overvaluation.

We draw two lessons from this analysis. At the most basic level, direct survey estimates of expectations are useful: they have a welldefined structure across different surveys, and they predict fund flows 
Table 1

Correlations among Different Measures of Investor Expectations of Stock Market Returns and Model-Based Expected Returns

\begin{tabular}{lcccccc}
\hline & Gallup & Survey & AAII & $\begin{array}{c}\text { Investor } \\
\text { Intelligence }\end{array}$ & Shiller & Michigan \\
\hline CFO Survey & 0.77 & & & & & \\
& {$[0.000]$} & & & & & \\
AAII & 0.64 & 0.56 & & & & \\
& {$[0.000]$} & {$[0.000]$} & & & & \\
Investor & 0.60 & 0.64 & 0.55 & & & \\
Intelligence & {$[0.000]$} & {$[0.000]$} & {$[0.000]$} & & & \\
Shiller & 0.39 & 0.66 & 0.51 & 0.43 & & \\
& {$[0.000]$} & {$[0.000]$} & {$[0.000]$} & {$[0.000]$} & & \\
Michigan & 0.61 & -0.12 & 0.60 & 0.19 & -0.56 & \\
& {$[0.003]$} & {$[0.922]$} & {$[0.003]$} & {$[0.395]$} & {$[0.020]$} & \\
Log(D/P) & -0.33 & -0.44 & -0.31 & -0.19 & -0.55 & -0.57 \\
& {$[0.000]$} & {$[0.003]$} & {$[0.000]$} & {$[0.000]$} & {$[0.000]$} & {$[0.006]$} \\
Cay & 0.02 & 0.14 & -0.02 & -0.19 & 0.37 & 0.00 \\
& {$[0.776]$} & {$[0.380]$} & {$[0.788]$} & {$[0.000]$} & {$[0.000]$} & {$[0.988]$} \\
Surplus & -0.48 & -0.53 & -0.28 & -0.05 & -0.67 & -0.74 \\
consumption & {$[0.000]$} & {$[0.000]$} & {$[0.000]$} & {$[0.191]$} & {$[0.000]$} & {$[0.000]$} \\
Past 12m stock & 0.78 & 0.36 & 0.37 & 0.43 & 0.05 & 0.44 \\
returns & {$[0.000]$} & {$[0.018]$} & {$[0.000]$} & {$[0.000]$} & {$[0.578]$} & {$[0.042]$} \\
Equity fund & 0.70 & 0.71 & 0.41 & 0.20 & 0.33 & 0.40 \\
flows & {$[0.000]$} & {$[0.000]$} & {$[0.000]$} & {$[0.000]$} & {$[0.000]$} & {$[0.068]$} \\
\hline
\end{tabular}

Note: This table shows correlations between different measures of investor expectations about future aggregate stock market returns, as well as correlations between survey expectations and discount rate proxies. Survey expectations variables are described in detail in Greenwood and Shleifer (2014). The CFO Survey refers to the Duke/CFO Magazine Survey, and AAII refers to surveys run by the American Association of Individual Investors. Investor Intelligence aggregates opinions expressed in newsletters published by institutional investors. Shiller denotes the survey led by Robert Shiller, and Michigan is University of Michigan Survey of Consumers. Horizon of survey expectations is mostly the next 12 months (Gallup, CFO Survey, Shiller); the AAII survey asks about next-6month expectations, and the horizon in Investor Intelligence and the Michigan survey varies. Among the discount rate proxies, $\log (\mathrm{D} / \mathrm{P})$ denotes $\log$ dividend yield, cay refers to the consumption-wealth ratio in Lettau and Ludvigson (2001), and surplus consumption is constructed by Campbell and Cochrane (1999). Discount rate proxies are presented in a way so that the value is increasing in model-based expected returns (we use the negative of surplus consumption because high surplus consumption should be associated with low expected returns). Numbers in brackets denote $p$-values on the hypothesis that the correlation between the two series is zero.

as well as future returns. Second, to the extent that survey estimates actually measure expectations is accepted, the evidence points against rational expectations models of stock market valuation. Actual expectations are strongly negatively related to the measures of expected returns that these models generate. In the remainder of this paper, we consider some related findings for corporate investment. 

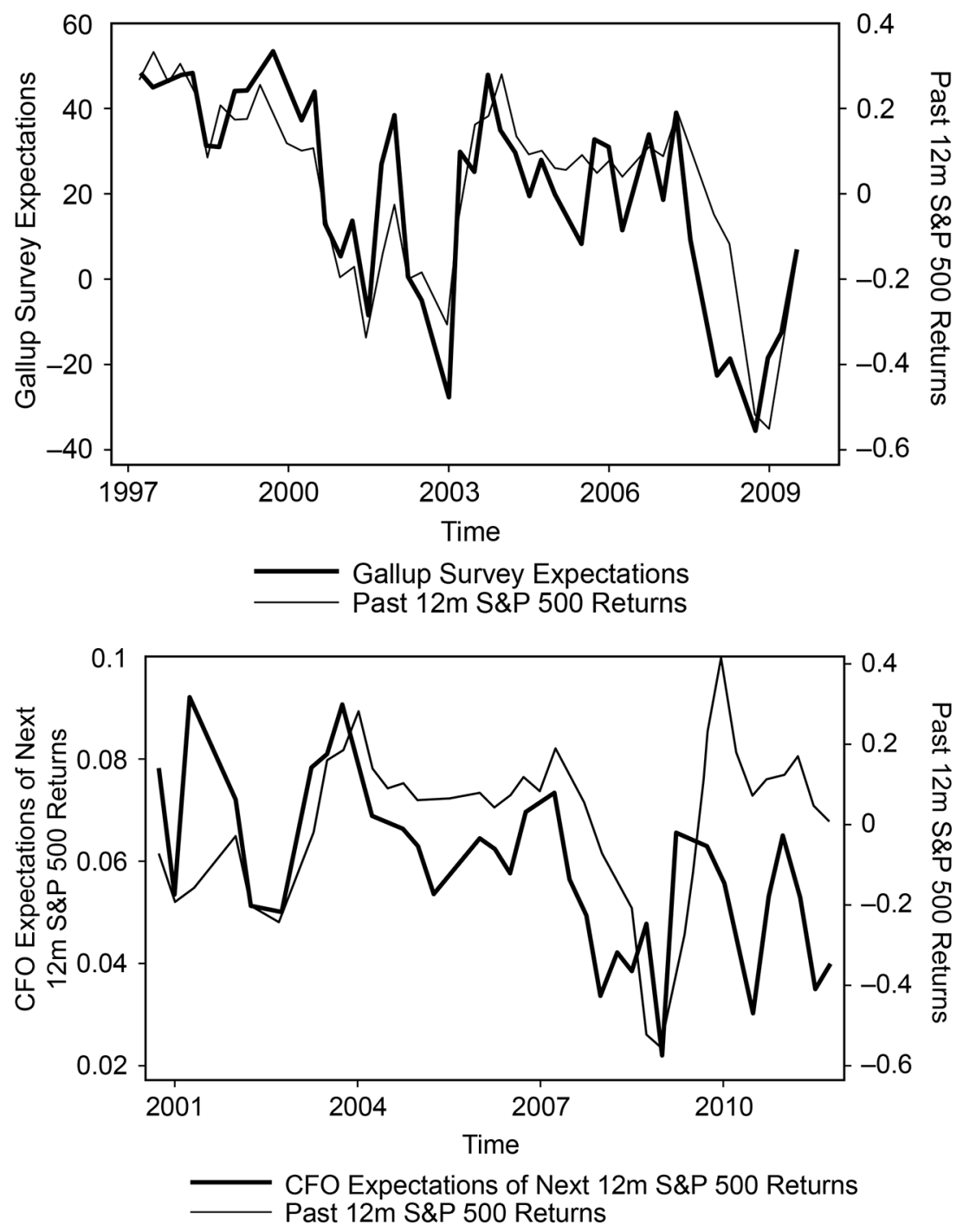

Fig. 1. Stock market expectations of investors and CFOs and past stock returns

Note: The thin line denotes S\&P 500 index returns in the past 12 months. In panel (A), the thick line denotes expectations from the Gallup survey (\% optimistic - \% pessimistic about performance of the stock market in the next 12 months). In panel (B), the thick line denotes the average response in the CFO survey, to the question "Over the next year, I expect the average annual S\&P 500 return will be: ." Frequency is quarterly. 


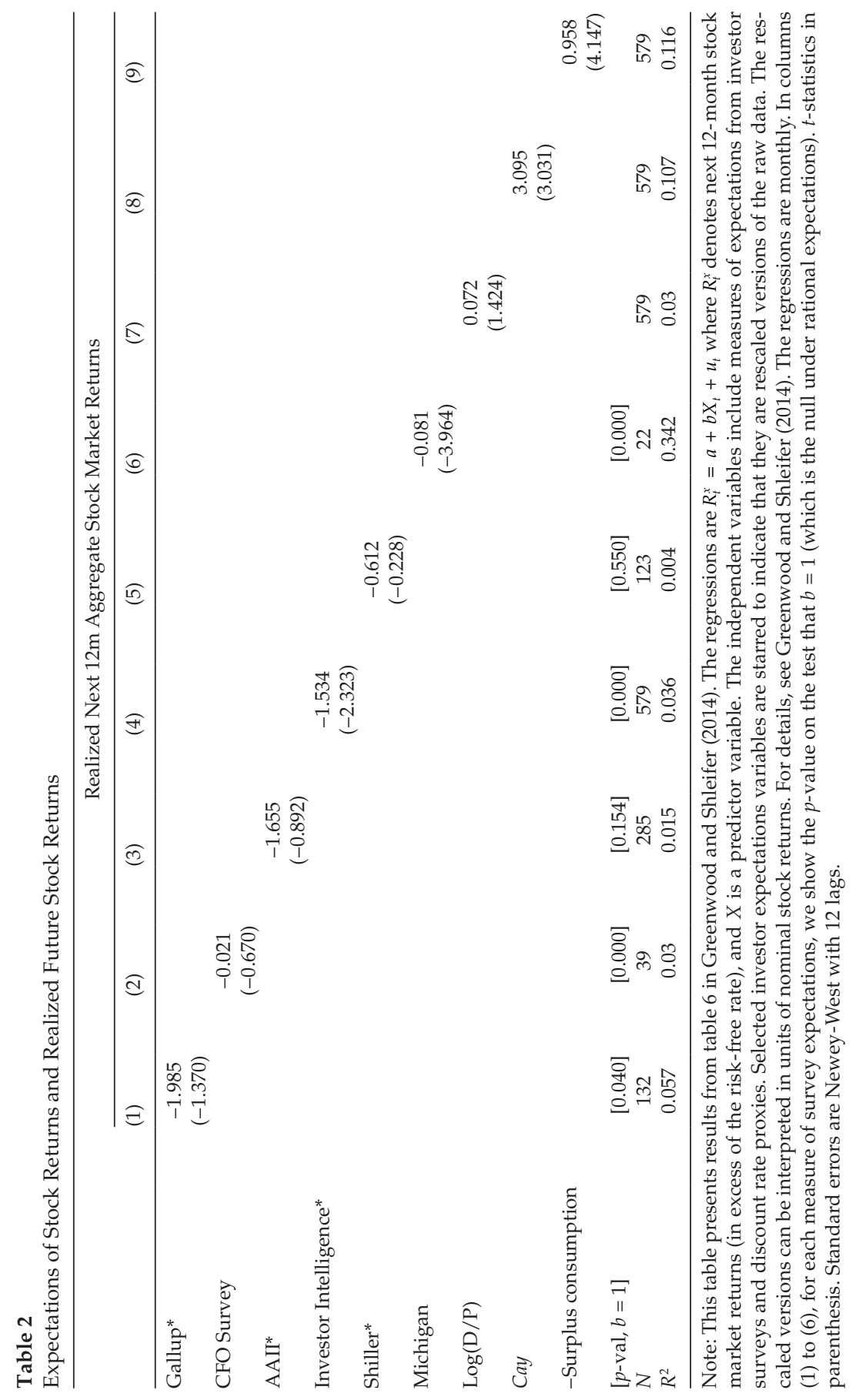




\section{Data for Studying Expectations and Investment}

Our empirical analysis of corporate investment draws on two main categories of data: (a) data on expectations, primarily of future profitability; and (b) data on firm financials and investment activities. We focus on nonfinancial firms in the United States. We collect data both at the aggregate and at the firm level, and all data are available at quarterly frequencies. Appendix B provides a list of the main variables, including their construction and the time range for which each variable is available. ${ }^{1}$

\section{A. Expectations Data}

We have data on the expectations of two groups of people: CFOs and equity analysts. We first describe these data and then show that expectations of CFOs and equity analysts are highly correlated.

\section{CFO Expectations}

Our data on CFO expectations come from the Duke/CFO Magazine Business Outlook Survey led by John Graham and Campbell Harvey, which was launched in July 1996 and takes place on a quarterly basis. Each quarter, the survey asks CFOs their views about the US economy and corporate policies, as well as their expectations of future firm performance and operational plans. ${ }^{2}$ Starting in 1998, the CFO survey consistently asks respondents their expectations of the future twelve-month growth of key corporate variables, including earnings, capital spending, and employment, among others. The original question is presented to the CFOs as follows:

Relative to the previous 12 months, what will be your company's PERCENTAGE CHANGE during the next 12 months? (e.g., $+3 \%,-2 \%$, etc.) [Leave blank if not applicable]

Earnings: ; Cash on balance sheet: ; Capital spending:

Prices of your product: ; Number of domestic full-time employees:

Wage: ; Dividends:

(Selected items are listed as examples. For a complete listing, please refer to original questionnaires posted on the CFO survey's website.)

We use CFOs' answers on earnings growth over the next 12 months as the main proxy for $\mathrm{CFO}$ expectations of future profitability. As the survey does not ask for expectations beyond the next 12 months, we 
will explain in Section IV how we interpret and extract information from earnings expectations over the next 12 months.

We then use CFOs' answers on capital spending growth in the next 12 months as a proxy for firms' current investment plans. In the empirical analysis, we investigate how investment plans relate to expectations of future profitability. We adopt this approach in light of well-documented lags between decisions to invest and actual investment spending (Lamont 2000). With lags in investment implementation, current expectations about future profitability may not translate into capital expenditures instantly. Instead, they will affect current investment plans, and show up in actual investment spending with some delay. As a result, it can be more straightforward to detect the impact of earnings expectations by looking at investment plans. We discuss this issue in more detail in sections IV and V.

Our analyses use both aggregate time-series and firm-level panel data. Aggregate variables are revenue-weighted averages of firm-level responses, and they are published on the CFO survey's website. While the survey does not require CFOs to identify themselves, some respondents voluntarily disclose this information. It is then possible to match a fraction of the firm-level responses with data from the Center for Research in Security Prices (CRSP) and Compustat to perform firm-level tests. For example, Ben-David, Graham, and Harvey (2013) use matched firm-level data to study how managerial miscalibration affects corporate financial policies. Because there are privacy restrictions associated with these data, Graham and Harvey helped us implement firm-level analysis using a subsample of their matched data set. The firm-level data we use has 1,133 firm-year observations, spanning from 2005Q1 to 2012Q4. ${ }^{3}$ We exclude firms that have negative earnings in the past 12 months because, in that case, earnings growth is not well defined. We also winsorize outliers at the $1 \%$ level.

\section{Analyst Expectations}

We obtain data on equity analysts' expectations of future firm performance from the Institutional Brokers' Estimate System (IBES) dataset. Beginning in the 1980s, IBES collects analyst forecasts of quarterly earnings per share (EPS) for the next 1 to 12 quarters. We take consensus EPS forecasts (i.e., average forecast for a given firm-quarter in the future) and compute forecasts of total earnings by multiplying by the number of shares outstanding. To compare the results with those using CFO expectations, we compute analyst expectations of future 12-month earnings growth. We calculate aggregate analyst expectations of future 12-month 
earnings growth by summing up expected future earnings of all firms in the next four quarters, and then divide by the sum of earnings of all firms in the past four quarters. We calculate firm-level analyst expectations of future earnings growth by taking the forecast of total firm earnings in the next four quarters, and then divide by total earnings in the past four quarters. We exclude firms that have negative earnings in the past 12 months when calculating expected future earnings growth.

The sample with analyst expectations covers both a longer time span and a larger set of firms. We set the start date of the aggregate time series and firm panel to be 1985Q1 because some of the quarterly Compustat data items we use only become systematically available around 1985, and because aggregate analyst forecasts have some outliers before 1985 . We set the end of the sample to be 2012Q4 so we can match expectations to realized next 12-month earnings growth with accounting data ending in 2013Q4. In total, we have 145,281 firm-level observations of expected earnings growth over the next 12 months, and we winsorize outliers at the $5 \%$ level.

\section{Correlation between $\mathrm{CFO}$ and Analyst Expectations}

The expectations of CFOs and analysts with respect to next 12-month earnings growth are highly correlated. Figure 2 shows aggregate time series of expected next 12-month earnings growth from the CFO survey and from analyst forecasts. The raw correlation between these two series is 0.65 . At the firm level, the raw correlation between $\mathrm{CFO}$ and analyst expectations of next 12-month earnings growth is 0.4 if we demean by firm, and 0.3 if we demean by both firm and time. The high correlation between expectations of CFOs and analysts indicate that expectations data are consistent and meaningful, and expectations of both groups incorporate information about general business outlook shared by managers and the market.

\section{B. Firm Financials Data}

We collect aggregate data on firm assets and investment from the Flow of Funds (table F.102 and table B.102) and the National Income and Product Accounts (NIPA), and firm-level data from Compustat. A key variable in our analysis is realized earnings, which we use to assess the accuracy of earnings expectations of CFOs and analysts. While Compustat mainly records Generally Accepted Accounting Principles (GAAP) earnings, managers and analysts often use so-called "pro forma earnings" (also 


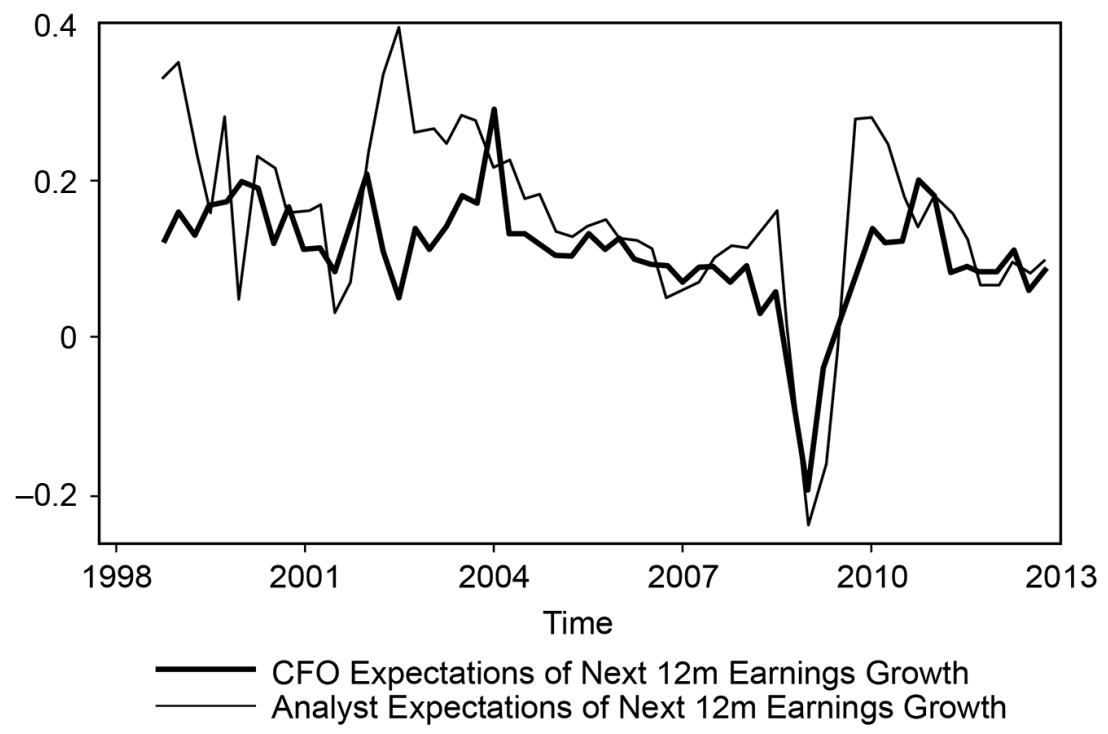

Fig. 2. Expectations of next-12-month earnings growth by CFOs and analysts Note: The thick line is aggregate CFO expectations of next-12-month earnings growth from the CFO survey. The thin line is aggregate analyst expectations of next-12-month earnings growth computed from analyst EPS forecasts. Frequency is quarterly.

called "street earnings"), which adjust for certain nonrecurring items (Bradshaw and Sloan 2002; Bhattacharya et al. 2003). To make sure we use the same measure of earnings as CFOs and analysts, we collect realized earnings from IBES Actuals files, which closely track earnings as reported by companies in their earnings announcements. These are the numbers that analyst forecasts aim to match and the earnings metric that managers tend to use the most. ${ }^{4}$ In the rest of the paper we refer to IBES actual earnings as "earnings," and GAAP earnings as "net income."

Table 3 presents summary statistics of firms for which we have firmlevel CFO expectations (panel A) and analyst expectations (panel B), as well as all nonfinancial firms in Compustat (panel C). For comparability, the statistics in panel (B) and panel (C) are generated based on the time period for which we have firm-level CFO expectations (i.e., from 2005 through 2012). We can see that firms with analyst expectations are mostly larger than the median Compustat firm, and firms with CFO expectations are generally even larger. Firms with $\mathrm{CFO}$ and analyst expectations also appear to be more profitable than firms in the full Compustat sample in terms of net income, but otherwise very similar in terms of sales, investment, book to market, and $q$. 


\section{Expectations and Firm Investment: Empirical Specifications}

We motivate our empirical specification with a basic $q$-theory model. A firm is run by a risk-neutral owner who discounts the future by factor $\beta<1,{ }^{5}$ and the firm's horizon is infinite. In the model, we interpret each period $t$ to be 12 months. The firm's output in period $t$ is obtained by combining capital and labor using a constant returns to scale production function $A_{t} K_{t}^{\alpha} L_{t}^{1-\alpha}$. At the beginning of period $t$, the owner hires labor $L_{t}$ at wage $w$ and makes decisions about investment during this year $I_{t}$. Investment takes one year to implement, so $K_{t+1}=(1-\delta) K_{t}+I_{t}$, where $\delta$ is capital depreciation rate. The firm's optimal policy in year $t$ maximizes the expected present value of earnings:

$$
\max _{\left\{I_{s},\left.L_{s}\right|_{s \geq t}\right.} \mathbb{E}_{t}\left\{\sum_{s \geq t} \beta^{s-t}\left[A_{s} K_{s}^{\alpha} L_{s}^{1-\alpha}-w L_{s}-C\left(I_{s}, K_{s}\right)\right]\right\}
$$

subject to $K_{s+1}=(1-\delta) K_{s}+I_{s}$. We assume the commonly used quadratic investment costs:

$$
C\left(I_{s}, K_{s}\right)-I_{s}=\frac{b}{2}\left(\frac{I_{s}}{K_{s}}-a\right)^{2} K_{s}
$$

which allow for convex adjustment costs $(b>0)$ and displays constant returns to scale.

In the optimization problem above, the operator $\mathbb{E}_{t}($.$) denotes the$ owner's expectations conditional on his information at the beginning of year $t$, computed according to his possibly distorted beliefs. We allow for departures from rational expectations, but restrict to beliefs that preserve the law of iterated expectations. By standard arguments, appendix $\mathrm{A}^{6}$ shows that the firm's optimal investment chosen at the beginning of year $t$ is described by:

$$
\frac{I_{t}}{K_{t}}=\left(a-\frac{1}{b}\right)+\frac{\beta}{b} \frac{\mathbb{E}_{t}\left[\Sigma_{s \geq t+1} \beta^{s-(t+1)} \Pi_{s}\right]}{K_{t+1}}
$$

where $\Pi_{s}=A_{s} K_{s}^{\alpha} L_{s}^{1-\alpha}-w L_{s}-C\left(I_{s}, K_{s}\right)$ denotes the firm's earnings in year $s$. Equation (1) corresponds to a generic $q$-theory equation with quadratic adjustment costs, which takes the form $I_{t} / K_{t}=\eta+\gamma Q_{t}$.

To estimate equation (1), ideally we would like to know expectations of earnings in all future periods. Unfortunately, this is not feasible in practice. For instance, CFOs only report expectations of earnings growth in the next 12 months. Formally, in the CFO survey we only have information about $\mathbb{E}_{t}\left(\Pi_{t}\right)$, namely expectations at the beginning of year $t$ about earnings $\Pi_{t}$ in the following 12 months (which are not yet known, 


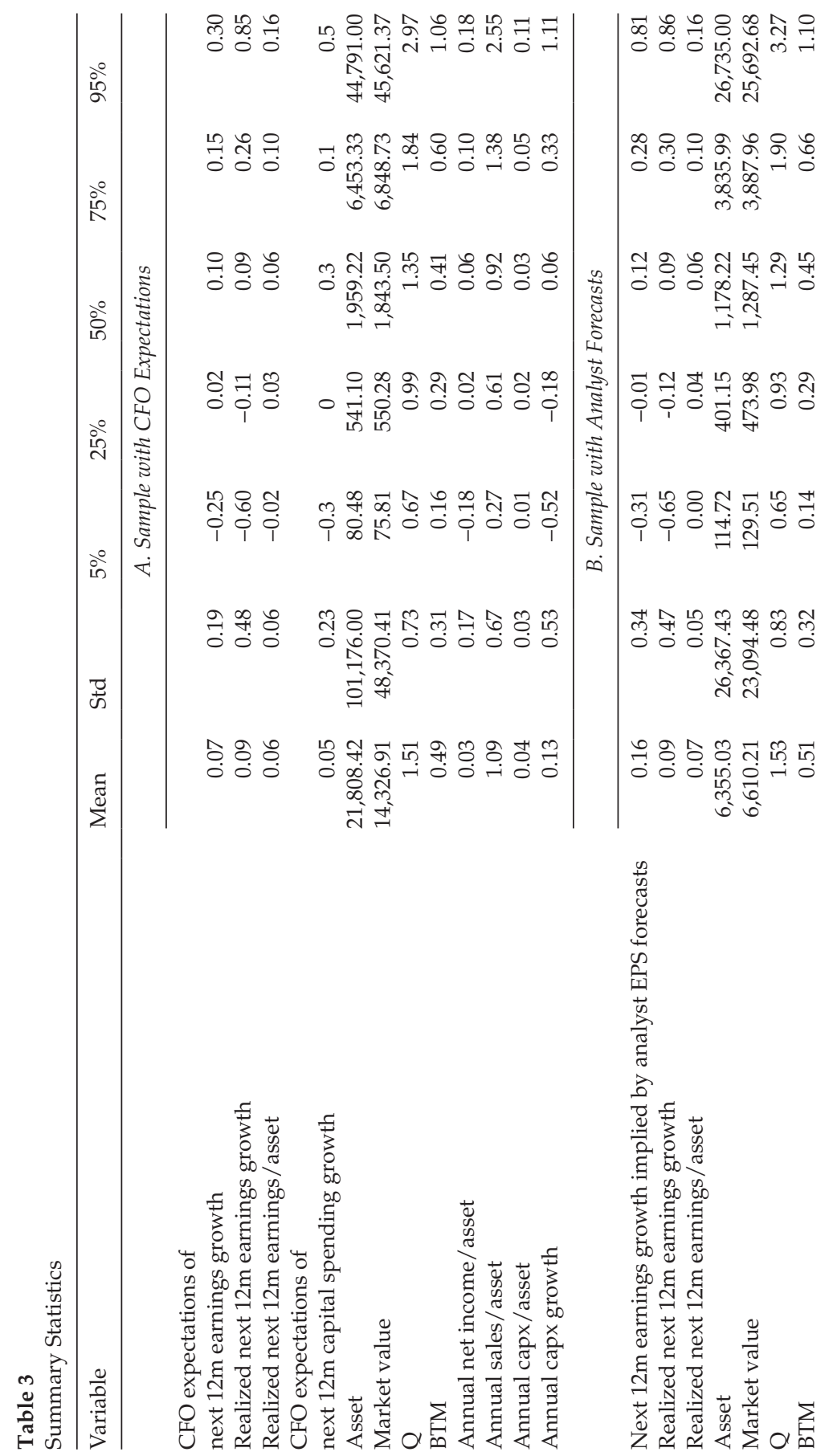




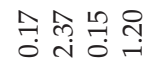

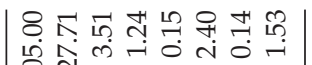

$$
\begin{aligned}
& \text { 势 }
\end{aligned}
$$

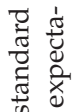

$$
\begin{aligned}
& \text { 웅 윰 }
\end{aligned}
$$

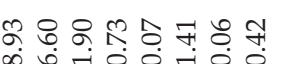

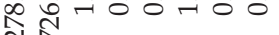

$$
\begin{aligned}
& \text { 독 }
\end{aligned}
$$

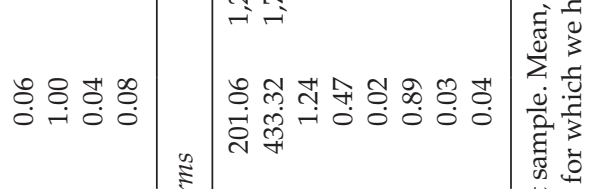

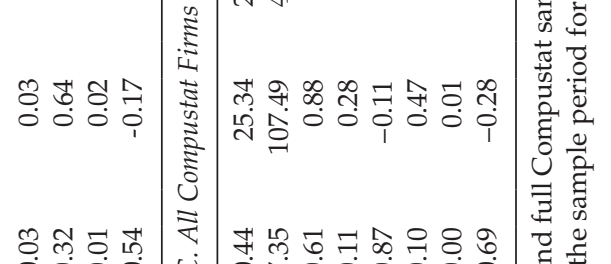

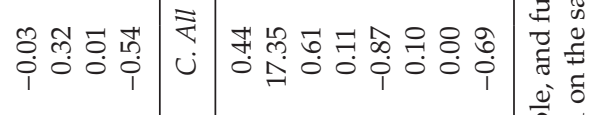

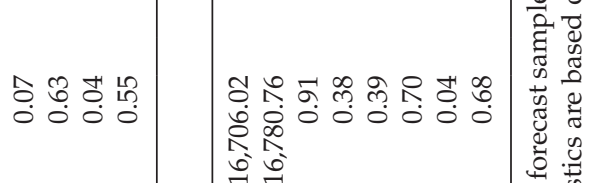

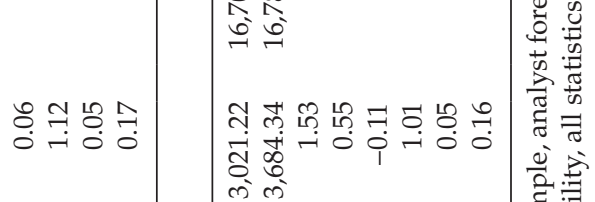

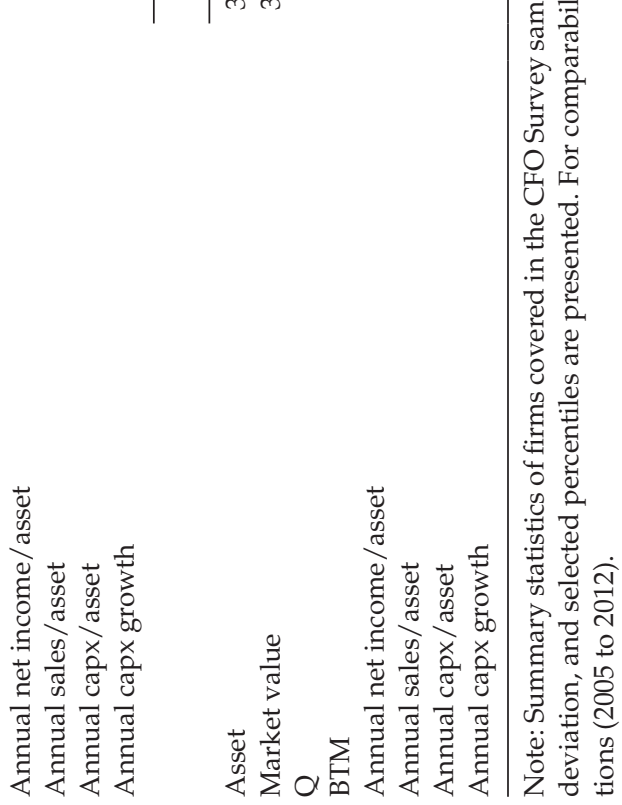


so expectations are well defined). With respect to investment, we have information on: (a) planned investment over the next 12 months, and (b) actual capital spending in each quarter. We denote investment plans for the next 12 months as $I_{t}^{p}$, which captures the plan made at the beginning of the year about investment in the rest of the year.

Given implementation lags in the investment process, it may be most straightforward to test how expectations at a given point in time affect firms' investment plans. ${ }^{7}$ Accordingly, we approximate equation (1) by

$$
\frac{I_{t}^{p}}{K_{t}} \approx \theta_{0}+\theta_{1} \frac{\mathbb{E}_{t}\left(\Pi_{t}\right)}{K_{t}}
$$

This approximation is reliable if expectations about the level of future earnings display significant persistence, namely $\mathbb{E}_{t}\left(\Pi_{t}\right) / K_{t}$ is not too far from $\mathbb{E}_{t}\left(\Pi_{t+1}\right) / K_{t+1}$ and more generally for earnings further away in the future. We find this assumption to be plausible based on information in the data. Empirically, earnings over assets are relatively persistent, and moreover, are perceived to be very persistent based on analyst forecasts. The IBES data set provides analysts' forecasts of future earnings for up to 12 quarters. With firm-level forecasts, we find $\mathbb{E}_{t}\left(\Pi_{i, t+1}\right) / K_{i, t+1}=0.83 \mathbb{E}_{t}\left(\Pi_{i, t}\right)$ $/ K_{i, t}+\eta_{i}+\varepsilon_{i, t}$ and $\mathbb{E}_{t}\left(\Pi_{i, t+2}\right) / K_{i, t+1}=0.73 \mathbb{E}_{t}\left(\Pi_{i, t}\right) / K_{i, t}+\eta_{i}+\varepsilon_{i, t}$. Aggregate persistence implied by analyst forecasts is similar. In addition, lagged profitability is not significant if included in these regressions and neither does it affect coefficients on $\mathbb{E}_{t}\left(\Pi_{i, t}\right) / K_{i, t}$. These results suggest that next one-year expectations incorporate a significant amount of information about medium- to long-term expectations. We showed in Section III that CFO and analyst expectations are highly correlated, and it is probable that their beliefs share common structures.

Given this corroborating evidence, it appears that within the limitations of our data, equation (2) is a reasonable approximation of equation (1). For the purpose of our empirical analysis, it is convenient to $\log$-linearize equation (2) and express it in growth rates, since all variables in the CFO survey are in terms of percentage change in the next 12 months relative to the past 12 months. By expressing equation (2) in growth rates, we can directly employ these variables without using them to reconstruct levels. If we denote logs by lowercase variables, then derivations in appendix $\mathrm{A}^{8}$ show that our equation for investment plans can be approximated as:

$$
\underbrace{i_{t}^{p}-i_{i-1}}_{\begin{array}{c}
\text { planned investment growth } \\
\text { in the next 12m }
\end{array}} \approx \mu_{1} \underbrace{\left[\mathbb{E}_{t}\left(\pi_{t}\right)-\pi_{t-1}\right]}_{\begin{array}{c}
\text { expectations of earnings growth } \\
\text { in the next 12m }
\end{array}}+\left(1-\mu_{1}\right)\left(k_{t}-k_{t-1}\right)
$$


where $\mu_{1}$ is a log-linearization constant $\left(\mu_{1}>0\right)$. The left-hand-side term is planned investment growth in the next 12 months, which is available from the CFO survey. The first term on the right-hand side of equation (3) is expectations of earnings growth in the next 12 months, which we also observe directly in the data. This specification is very similar to previous studies of investment growth such as Barro (1990), Lamont (2000), and many others.

The intuition of equation (3) is as follows: When firms think that earnings will increase by a lot in the next 12 months, they also tend to believe that future earnings will be higher for a sustained period of time. As a result, they want to invest more, which leads to an immediate increase in planned investment. In equation (3) we need to control for the change in capital stock because both investment and profitability are affected by the size of capital stock. We can also arrive at a specification very similar to equation (3) in a simpler setting with time to build but without adjustment costs. ${ }^{9}$ Empirically we use equation (3) to map a basic investment model to testable predictions in our data set. We refrain from testing the parameter restrictions implied by a strict adherence to the approximated $q$ equation.

While investment plans are a convenient starting point to detect the impact of expectations, for equation (2) to be informative about how expectations influence investment, it must also be the case that plans are closely related to realizations. In Section V.C, we show that investment plans are highly correlated with actual capital spending over the planned period. In other words, a significant fraction of capital spending over the next few quarters appears to be determined by ex ante investment plans, consistent with previous findings by Lamont (2000). To the extent that there is a close correspondence between investment plans and realized investment over the planned period, it would also be of interest to test how current expectations translate into actual capital spending in the next 12 months. This additional test allows us to further assess whether expectations have a substantial impact on actual investment activities. We present results from these tests in Section V.C.

\section{Expectations and Investment}

In this section, we test the relationship between investment decisions and earnings expectations. We focus on $\mathrm{CFO}$ expectations, and provide supplementary results using expectations of equity analysts. We begin by studying investment plans. In Section V.A we consider the role of expectations at the aggregate level, and in Section V.B we consider the 
role of expectations at the firm level. Then, in Section V.C we evaluate the relationship between plans and realized investment, and document the link between expectations and actual capital spending.

\section{A. Expectations and Investment Plans: Aggregate Evidence}

Figure 3 visually represents the association between aggregate $\mathrm{CFO}$ expectations and aggregate investment. Panel (A) plots CFOs' expectations of next 12-month earnings growth, along with planned investment growth in the next 12 months. Panel (B) adds to panel (A) actual aggregate investment growth in the next 12 months. We see that there is a strong comovement between earnings expectations and investment plans, and between investment plans and actual capital spending. At the very least, expectations data do not appear to be uninformative noise.

We then estimate versions of equation (3) using quarterly regressions:

$$
\Delta \widehat{\operatorname{CAPX}}_{\mathrm{q}_{t}}=\alpha+\beta \mathrm{E}_{\mathrm{q}_{t}}^{*}[\Delta \text { Earnings }]+\lambda \mathrm{X}_{\mathrm{q}_{t}}+\epsilon_{\mathrm{q}_{t}}
$$

where $\Delta \widehat{\mathrm{CAPX}}_{\mathrm{q}_{t}}$ is planned investment growth in the next 12 months reported in quarter $\mathrm{q}_{t}$, and $\mathrm{E}_{\mathrm{q}_{t}}^{*}$ [ $\Delta$ Earnings] is CFO expectations of next 12month earnings growth reported in quarter $\mathrm{q}_{t ;} \mathrm{X}_{\mathrm{q}_{t}}$ includes past change in capital stock as shown in equation (3), as well as a set of additional controls we discuss below. We use Newey-West standard errors with twelve lags. ${ }^{10}$

Table 4, columns (1) and (2), report our baseline results. We find that CFOs' earnings expectations have significant explanatory power for firms' investment plans, both statistically and economically. A one standard deviation increase in earnings growth expectations is associated with a 0.8 standard deviation increase in planned investment growth. ${ }^{11}$ Put differently, a 1 percentage point increase in CFO expectations is accompanied by a 0.6 percentage point increase in planned investment growth. ${ }^{12}$ Quantitatively, $\mathrm{CFO}$ expectations have major explanatory power for aggregate investment.

In interpreting these results, three issues arise. First, how do CFO expectations relate to traditional proxies of Tobin's $q$ ? Do data on managers' expectations contain information beyond market-price-based measures of $q$ ? Second, is the role of expectations robust to controlling for alternative theories of corporate investment? Third, could the correlation between expectations and investment reflect a reverse causality problem, whereby investment affects expectations of future earnings rather than the other way around? In the following, we address these issues by augmenting our baseline regressions. 


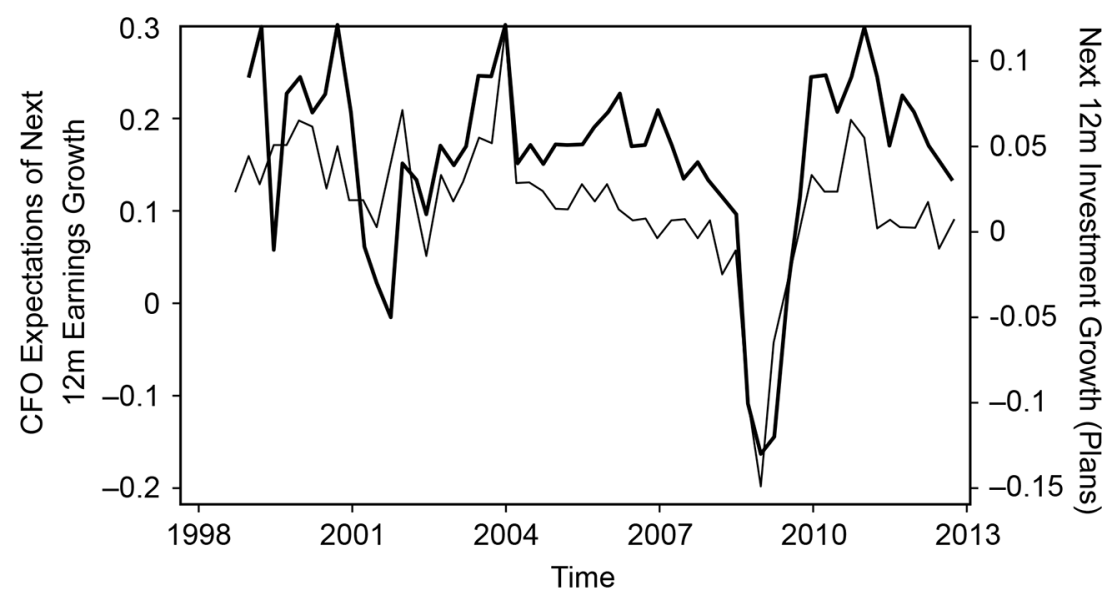

CFO Expectations of Next $12 \mathrm{~m}$ Earnings Growth

Next $12 \mathrm{~m}$ Investment Growth (Plans)

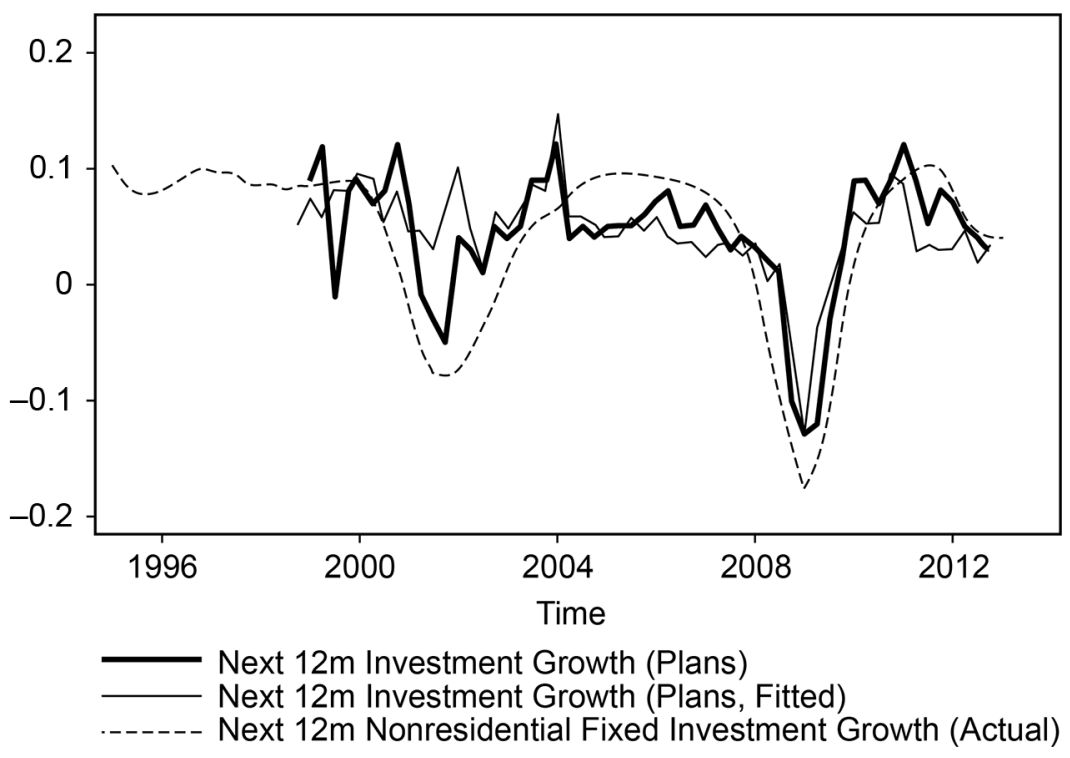

Fig. 3. CFO earnings growth expectations and investment

Note: The plots above present aggregate CFO expectations of future earnings growth, aggregate planned investment growth, and aggregate actual investment growth. In panel (A), the thin line is aggregate CFO expectations of next-12-month earnings growth. The thick line is aggregate planned investment growth in the next 12 months. In panel (B), the thin line is planned investment growth in the next 12 months fitted on contemporaneous $\mathrm{CFO}$ earnings growth expectations. The thick line is aggregate planned investment growth in the next 12 months. The dashed line is actual growth of private nonresidential fixed investment in the next 12 months. Frequency is quarterly. 


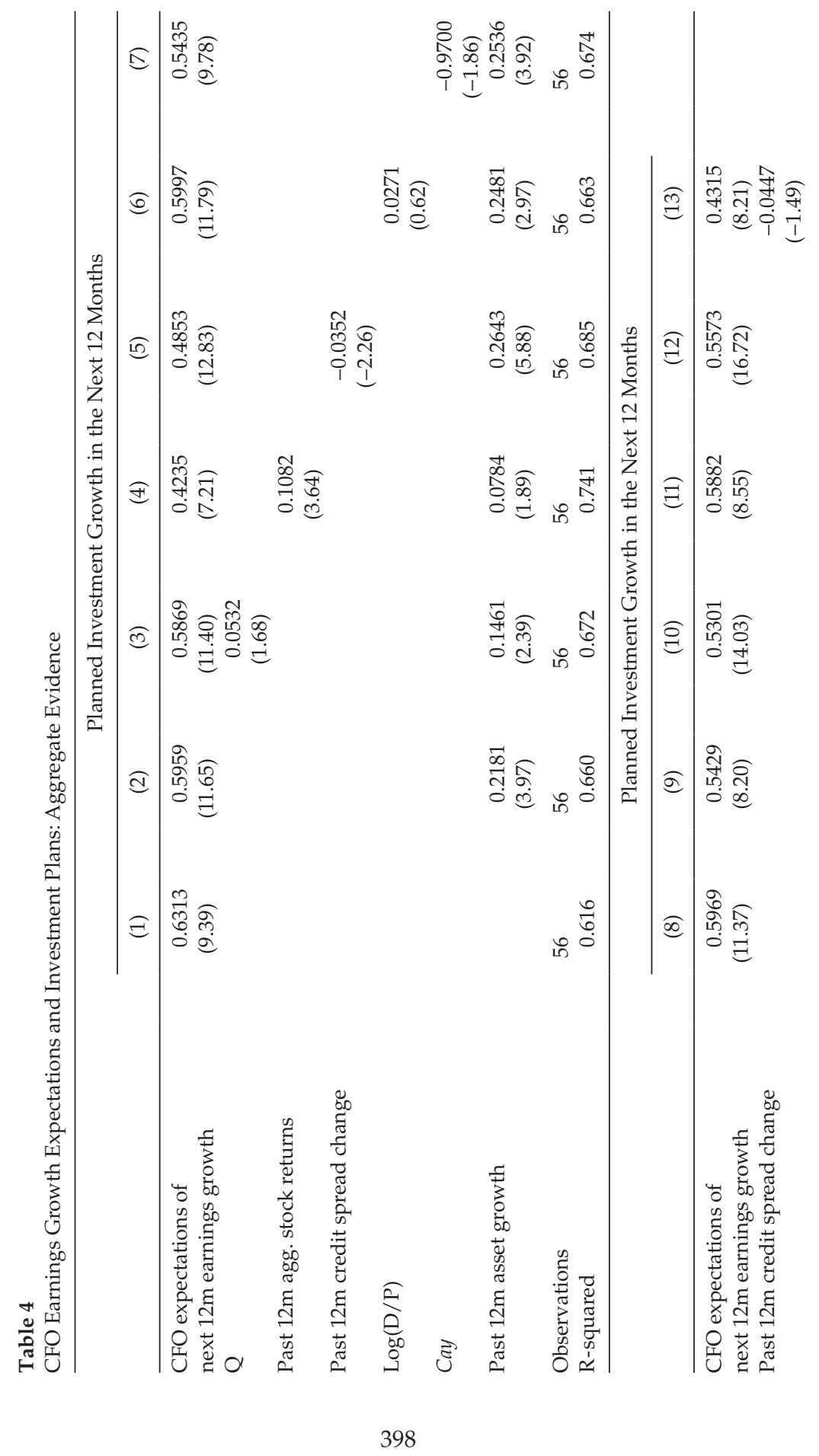




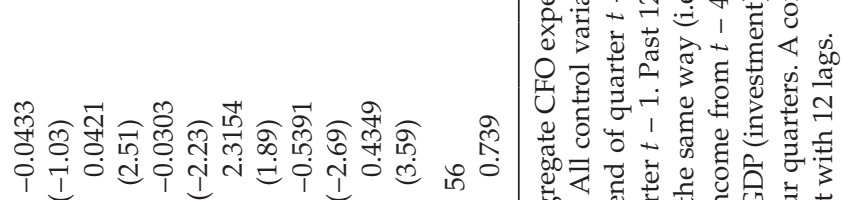

$$
\begin{aligned}
& \text { i }
\end{aligned}
$$

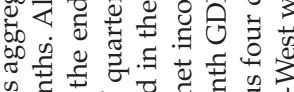

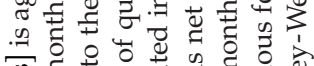

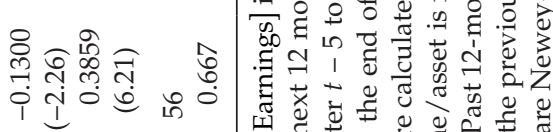

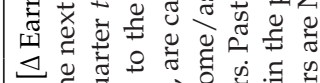

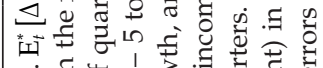

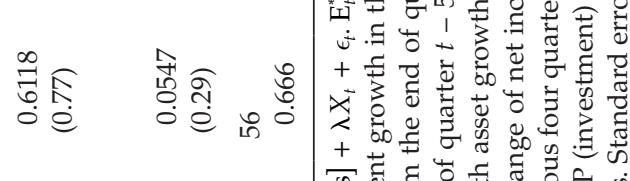

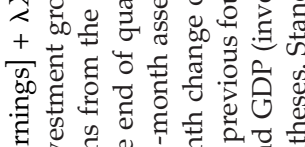

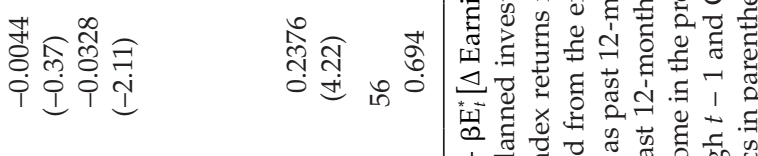

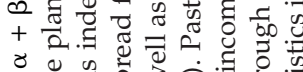

$$
\begin{aligned}
& \text { 率 } \\
& \text { 苦号 }
\end{aligned}
$$

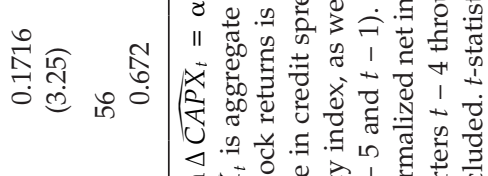

$$
\begin{aligned}
& \text {. क }
\end{aligned}
$$

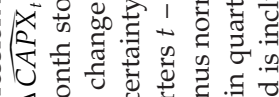

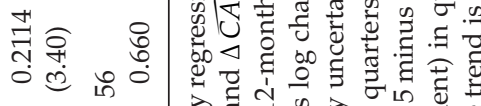

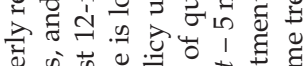

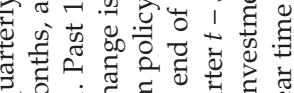

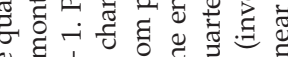

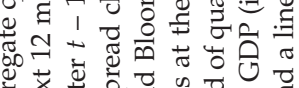

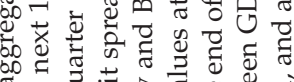

$$
\begin{aligned}
& \text { 年 }
\end{aligned}
$$

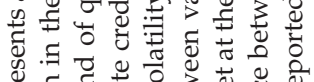

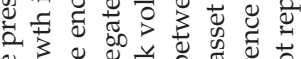

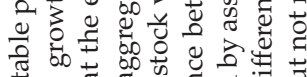

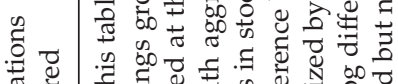

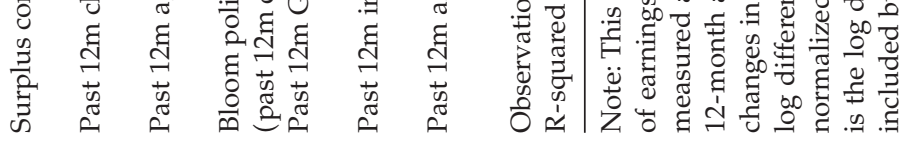


Some variables may affect investment but are likely to do so only through their influence on expectations, such as information relevant for predicting future product demand. In principle, a large part of expectations are formed, perfectly or imperfectly, based on observable information, instead of being exogenous innovations. Thus a flexible enough function of observable information should be able to approximate expectations. The focus of our present analysis is to test the extent to which expectations as a whole, as measured in our data, affect firms' investment decisions. It is not specifically about the impact of variations in expectations that are not explained by observables (so-called "expectational shocks"). Accordingly, we do not explore whether our expectations variables can or cannot be driven out by a full set of factors that are primarily used to explain expectations. Instead, we emphasize controls that represent alternative determinants of investment (such as discount rates, financial constraints, etc.). ${ }^{13}$

\section{CFO Expectations and Market-Based Proxies for Tobin's $q$}

We begin with a comparison of CFO expectations and traditional proxies of Tobin's $q$. This exercise helps us assess whether expectations data contain additional information relative to standard market-based $q$ measures. In table 4, column (3), we include the empirical proxy of $q$. In line with previous research, the explanatory power of equity $q$ is very weak. It is well known that equity $q$ is highly persistent and does not line up well with fluctuations in investment activities. In our context, to explain investment growth, the direct theoretical counterpart is not $q$ in levels, but the log change in $q$. Barro (1990) shows changes in $q$ are almost equivalent to stock returns. He finds that changes in $q$ from the beginning of year $t-1$ to the beginning of year $t$ is highly correlated with investment growth in year $t$, and stock returns from the beginning of year $t-1$ to the beginning of year $t$ perform incrementally better. In column (4), we include past 12-month stock returns. The coefficient on this variable is positive and statistically significant, as predicted by theory. The coefficient on CFO expectations remains large and highly significant. ${ }^{14}$ The views of CFOs appear to contain a substantial amount of additional information for investment plans not captured by equity $q$.

Philippon (2009) finds that a proxy of $q$ obtained from bond yields is also highly correlated with investment activities. Philippon's bond $q$ series end in 2007, which is five years before the end of our sample. How- 
ever, bond $q$ is highly correlated with credit spread. For example, the correlation between changes in bond $q$ and changes in credit spread over four quarters is 0.84 . In column (5), we include changes in credit spread in the past four quarters in lieu of bond $q$. In addition, credit spread can be relevant as a control also because it may reflect credit availability and financial constraints. The coefficient on this variable is negative and significant-consistent with theory-but CFO expectations retain significant explanatory power.

Overall, CFO expectations explain investment plans beyond marketbased $q$ proxies, statistically and economically. Indeed, CFOs may possess information that markets participants either do not possess or process imperfectly. To the extent that managers' and markets' views differ, it is natural that managers' beliefs have a major impact on investment decisions. As we show in Section V.C, this result also extends to actual capital spending.

\section{CFO Expectations and Alternative Theories of Investment}

We now test the role of expectations against alternative theories of investment. We introduce a set of variables motivated by these theories, which are the key controls in our analysis.

Time-Varying Discount Rates. A prominent idea in traditional finance holds that variations in required returns, or discount rates, are central to explaining investment in both financial and real assets (e.g., Cochrane 1991, 2011). Lamont (2000) postulates that firm investments rise and fall in response to changes in discount rates so that high investment growth is associated with low future stock returns. Lettau and Ludvigson (2002) argue that time-varying risk premia, as proxied for by the consumption-wealth ratio (known as cay), can forecast future investment growth. In table 4, columns (6) to (8), we control for three common measures of discount rates: log dividend yield, cay, and the surplus consumption ratio as constructed by Campbell and Cochrane (1999). Cay is somewhat significant, surplus consumption is not, and dividend yield tends to enter with the wrong sign. The explanatory power of CFO expectations is unaffected. We get similar results if we include these variables in past 12-month changes instead of in levels.

We can also control for risk premia implied by long-run risks models, as constructed by Bansal et al. (2014). Unfortunately their series is annual, which leaves us with few observations. We interpolate the series 
to quarterly frequencies in multiple ways and find it tends to enter with the wrong sign. Taken together, none of these variables compare in their explanatory power to CFO expectations, and their inclusion does not have much of an influence on the coefficient on expectations. ${ }^{15}$

Because proxies for discount rates are generally quite persistent, their coefficients can suffer from Stambaugh (1999) biases. In our case, Stambaugh bias will tend to attenuate the coefficients on discount rates toward zero or make them have the wrong sign. ${ }^{16}$ In appendix $C$, table $\mathrm{C} 6,{ }^{17}$ we report Stambaugh bias-adjusted results, using a multivariate version of the bootstrap method in Baker, Taliaferro, and Wurgler (2006). The bias adjusted results are very similar.

Financing Constraints. A well-known empirical result, dating back to Fazzari, Hubbard, and Petersen (1988), is that investment is positively correlated with recent firm cash flows. The leading interpretation is that financially constrained firms invest more when high cash flows increase internal resources. In column (9), we control for cash flows in the past 12 months. ${ }^{18}$ We can include cash flow variables either in levels or in changes, and results are similar: the coefficient on expectations barely changes, and the coefficient on past cash flows tends to be insignificant. This result confirms earlier findings by Cummins et al. (2006) that unveil the fragility of financial constraint variables once earnings expectations are taken into account.

Economic Uncertainty. A blooming literature studies the impact of uncertainty on economic activities when investment is irreversible or has fixed adjustment costs (Leahy and Whited 1996; Guiso and Parigi 1999; Bloom, Bond, and Van Reenen 2007; Bloom 2009, among others). During periods of high uncertainty, the theory goes, managers do not want to exercise the option of investing: they prefer to wait for better times and information. It is legitimate to ask whether our measure of $\mathrm{CFO}$ expectations still matters when we include proxies for uncertainty in our regression.

In table 4, column (10), we include stock price volatility as a standard uncertainty proxy following Leahy and Whited (1996) and Bloom, Bond, and Van Reenen (2007), together with economic policy uncertainty as measured by Baker, Bloom, and Davis (2015). We can use these variables in levels or in past 12-month changes. In either case, these uncertainty proxies have only weak explanatory power, and the coefficient on CFO earnings expectations remains highly significant. 
In table 4, columns (11) and (12), we additionally control for past GDP growth and past investment growth. In the last column, we include multiple controls together. The statistical and economic significance of $\mathrm{CFO}$ expectations remains largely intact.

Overall, these tests illustrate that $\mathrm{CFO}$ earnings expectations have significant explanatory power that is not accounted for by variables capturing alternative theories, such as time-varying discount rates, financial constraints, and uncertainty. As we show below, similar results hold when we connect expectations to actual capital spending. Our results suggest that expectations data provide substantive information about fluctuations in aggregate investment, and changes in expectations can be central to understanding investment activities.

\section{Reverse Causality}

One possible concern is our baseline results could be affected by reverse causality. Specifically, if a firm plans to invest a lot in the next 12 months, managers might also expect earnings to increase as investment leads to more output and sales. This mechanism seems unlikely to be driving our results. First, investment in the next 12 months generally does not translate into output and sales immediately. Second, even if it does, investment is an incremental addition to the capital stock. It is unlikely that a $1 \%$ increase in investment (which increases the firm's capital stock by much less than $1 \%$ ) can instantly lead to a $1 \%$ or more increase in firm earnings, as would be required to match the magnitude of coefficients in the data.

We further address the reverse causality concern in supplementary tests, drawing on another question in the CFO survey, which asks respondents to rate their optimism about the US economy on a scale from 0 to 100 (with 0 being the least optimistic and 100 the most optimistic). In appendix $\mathrm{C}$, table $\mathrm{C} 1$, we show that CFOs' optimism about the US economy is significantly positively correlated with investment. It is hard to argue that firms' investment plans will mechanically cause CFOs to be more optimistic about the US economy. Instead, this result is very much in line with previous findings that firms' expectations and sentiments appear to be a key driver of investment activities.

In appendix $\mathrm{C}$, table $\mathrm{C} 2$, we present the same set of tests using analyst expectations. We find analyst expectations are also significantly correlated with investment plans, although not surprisingly, the magnitude of the relationship is smaller; the coefficients on analyst expectations are 
generally about one-half of the size of the coefficients on CFO expectations. The evidence suggests that expectations elicited from different sources are consistent, and there are general views shared by managers and the market that play an important role in shaping aggregate investment dynamics.

\section{B. Expectations and Investment Plans: Firm-Level Evidence}

In table 5, we repeat our analysis at the firm level. As before, we start with CFO data. We estimate

$$
\Delta \widehat{\operatorname{CAPX}}_{\mathrm{i}, \mathrm{q}_{t}}=\alpha+\zeta_{i}+\beta E_{i, \mathrm{q}_{t}}^{*}\left[\Delta \text { Earnings }_{i}\right]+\lambda \mathrm{X}_{\mathrm{i}, \mathrm{q}_{t}}+\epsilon_{\mathrm{i}, \mathrm{q}_{t}} .
$$

We report baseline results with firm fixed effects. Results are very similar without fixed effects, or with dynamic panel estimators. ${ }^{19}$ Table 5 shows that at the firm level, CFO expectations continue to have substantial explanatory power for investment decisions. The response of a firm's investment plans to CFO expectations is similar in magnitude to the relationship unveiled in the aggregate analysis of table 4: when CFOs expect earnings growth to increase by 1 percentage point, planned investment growth increases by 0.4 percentage points on average. We then compare CFO expectations with firm-level $q$ and past 12-month firm stock returns. We use the book-to-market ratio as a proxy for firmlevel required returns, and all other firm-level controls directly correspond to their aggregate counterparts in table 4. After including these controls, alone or together, $\mathrm{CFO}$ expectations remain statistically and economically significant. We also examine results adding time fixed effects and the findings are similar.

In appendix C, table C3, we replicate the firm-level analysis with analyst expectations. The results show that analyst expectations about a firm's earnings growth can also explain investment plans. As before, the size of the coefficients on analyst expectations is about one-half of that on CFO expectations. While CFO expectations play a more dominant role, business outlook shared by managers and specialist analysts is nonetheless informative about investment decisions.

\section{From Plans to Realized Investment}

A premise for our analysis in Sections V.A and V.B is that investment plans are key determinants of actual capital spending. With lags in investment implementation, expectations in a given quarter may not trans- 
late into realized investment instantly, so changes in plans can help us pinpoint the impact of expectations, and plans will turn into capital expenditures over a period of time. In this section, we evaluate this proposition empirically. In figure 3, panel (B), it is evident that, at the aggregate level, plans and realized investment over the planned period are closely related. The raw correlation between the two series is $0.78 .{ }^{20}$ Figure 3, panel (B), also shows that realized investment is highly correlated with investment plans fitted on CFO expectations. Expectations are a key driver not only of investment plans, but also of actual capital spending.

In table 6 and table 7, we present a full set of results using CFO earnings expectations in a given quarter to forecast actual investment growth in the next 12 months, both in the aggregate and at the firm level. We find that expectations, and CFO expectations in particular, have substantial forecasting power for realized next 12-month investment. Both in the aggregate and at the firm level, a 1 percentage point increase in $\mathrm{CFO}$ earnings growth expectations predicts a 0.6 percentage point increase in actual investment growth in the next 12 months. The performance of past stock returns and changes in credit spread has some improvements, but expectations data retain significant power; they are very informative about realized capital spending both alone and in the presence of a list of important controls.

Taken together, evidence in this section shows that expectations data are highly relevant for understanding corporate investment. They are not simply noise, but contain considerable information for explaining investment activities beyond a host of traditional variables.

\section{Are Expectations Rational?}

Since expectations shape investment, it is critical to understand their determinants. We now take a first step in analyzing the structure of $\mathrm{CFO}$ and analyst expectations about future earnings growth. In particular, we check whether expectations of managers and market participants are consistent with rational benchmarks, or are systematically biased in predictable ways.

The simplest test of rational expectations is to run a regression with realized future earnings growth on the left-hand side and ex ante expectations on the right-hand side. In our context, such tests take the form:

$$
\underbrace{\Delta \text { Earnings }_{i}}_{\begin{array}{c}
\text { realized next 12m } \\
\text { earnings growth }
\end{array}}=\alpha+\beta \underbrace{E_{i, q_{t}}^{*}\left[\Delta \text { Earnings }_{i}\right]}_{\begin{array}{r}
\text { expected next 12m } \\
\text { earnings growth }
\end{array}}+\omega_{i, t+1}
$$




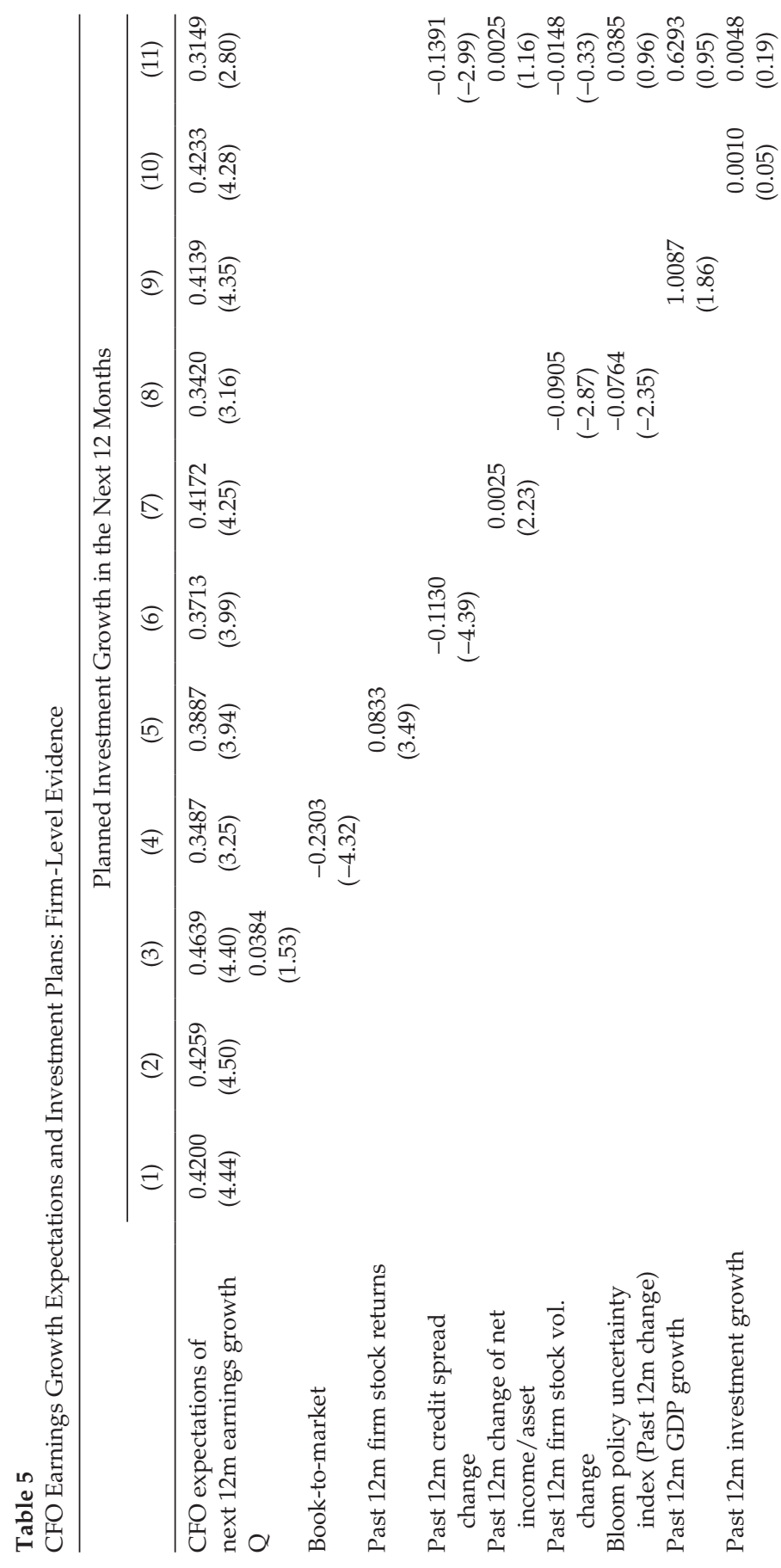




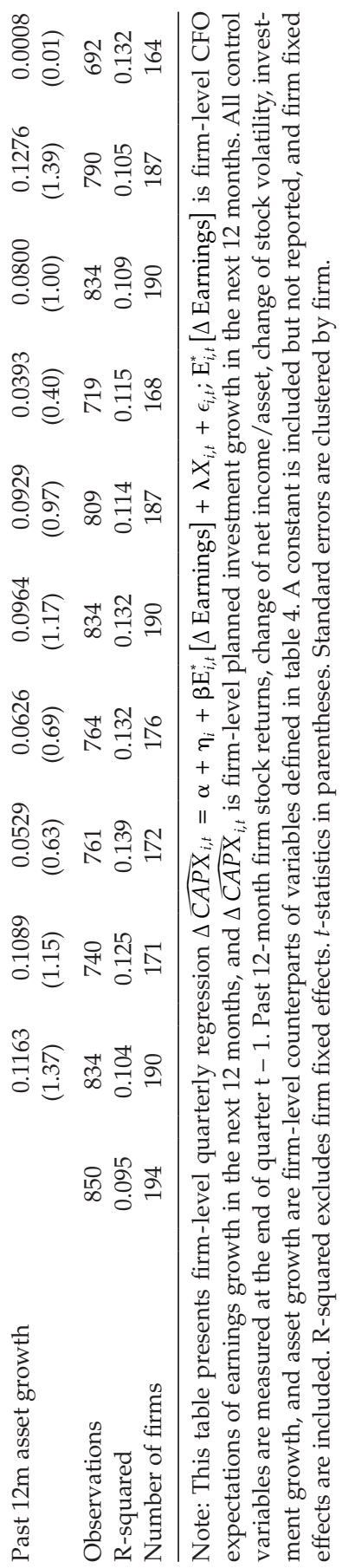




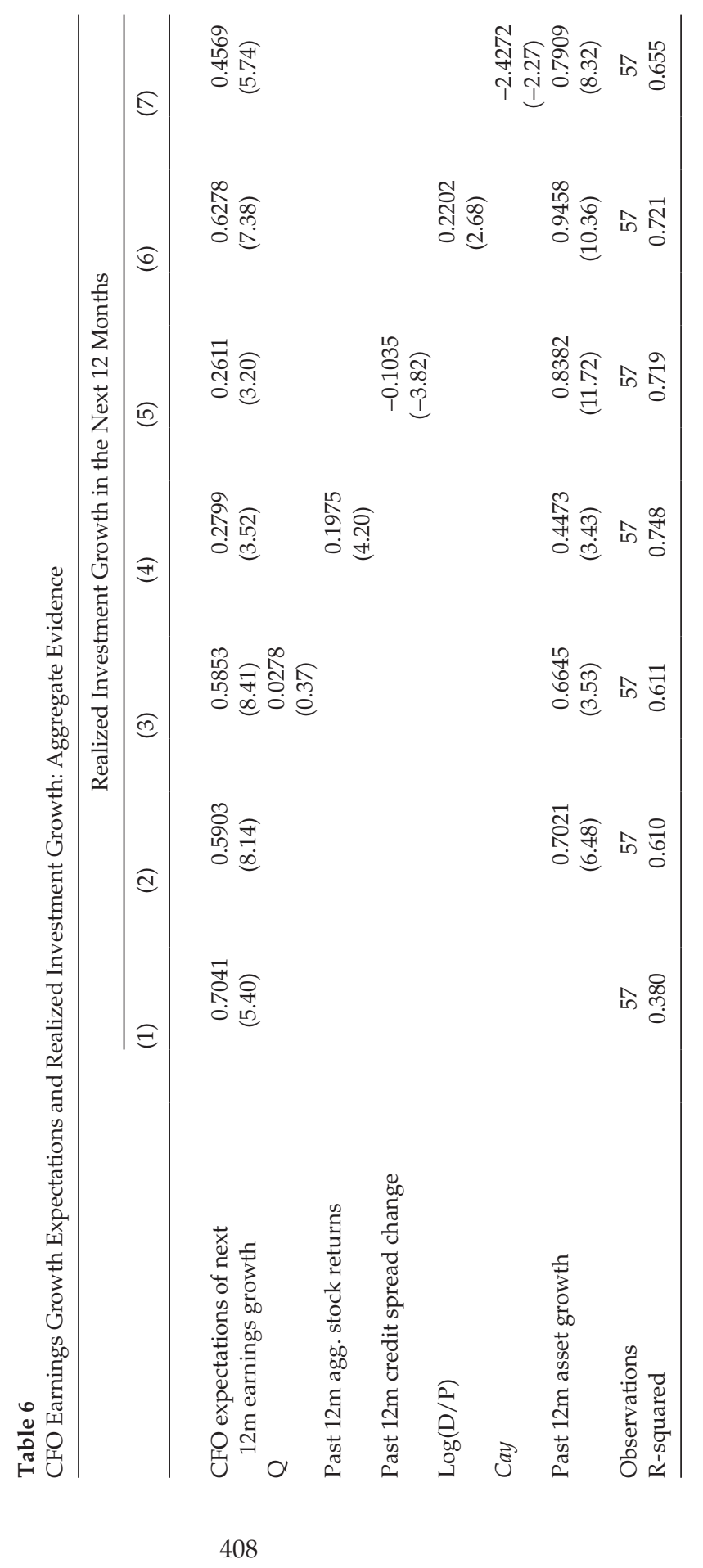




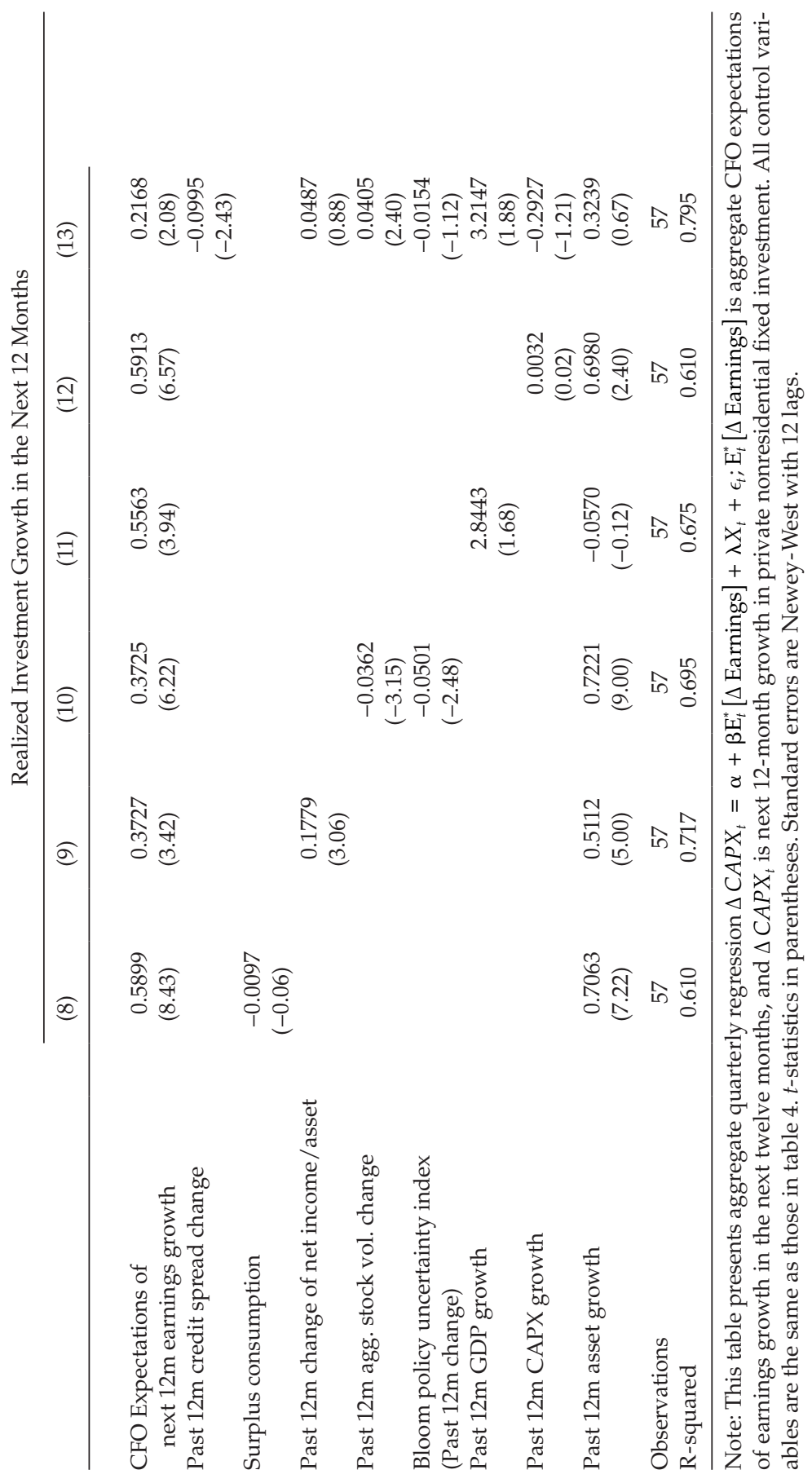




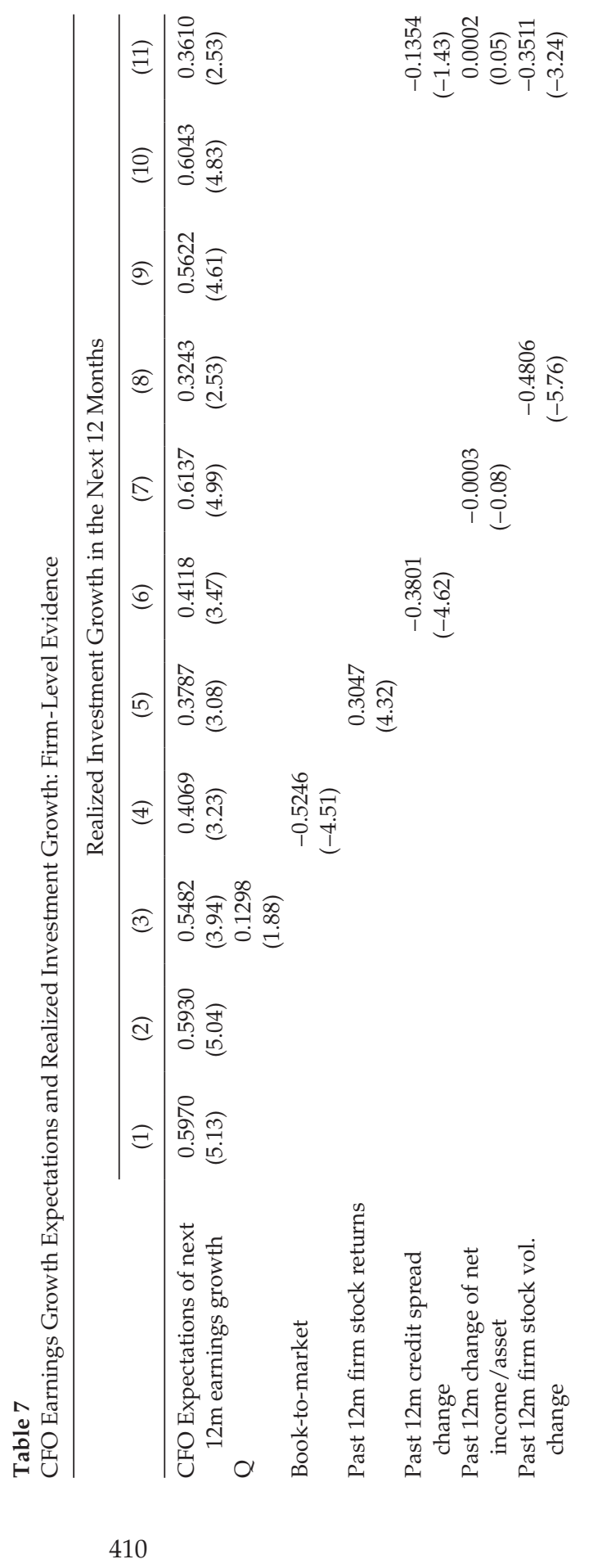




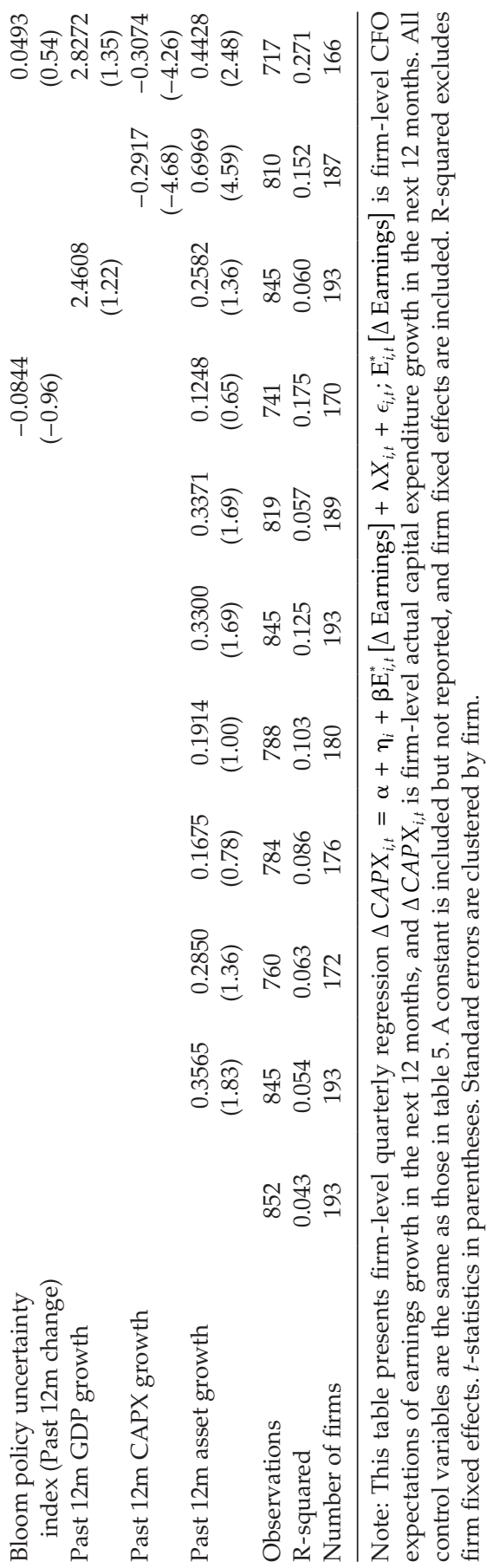


where $i$ is a firm index, $\Delta$ Earnings $_{i}$ denotes realized earnings growth in the next 12 months, and $\mathrm{E}_{i, \mathrm{q}_{t}}^{*}\left[\Delta\right.$ Earnings $\left._{i}\right]$ denotes expectations of next 12 -month earnings growth reported in quarter $\mathrm{q}_{t}$. The test can be augmented by including on the right-hand side a set of variables that are within time $t$ information set.

Rational expectations postulate that $\alpha=0$ and $\beta=1$ (and a zero coefficient on any other variable in time $t$ information set). Using both CFO and analyst expectations, we find $\beta$ to be significantly lower than 1 , and a list of variables known at time $t$ enter significantly. This finding, however, does not necessarily mean that expectations are excessively volatile relative to outcomes. It could be that expectations are measured with error, which would cause a downward bias in $\beta$.

An alternative approach is to study the predictability of ex post expectational errors. If expectations are rational, forecast errors should be orthogonal to all information available at the time when the forecast is made, and forecast errors should be unpredictable. If, on the other hand, expectations are systematically biased, then ex post errors would be predictable using information available ex ante. In this case, the structure of error predictability could help us understand potential sources of excessive optimism and pessimism.

To take a first look, consider figure 4. Panel (A) shows errors in aggregate $\mathrm{CFO}$ expectations about next 12-month earnings growth against past year corporate profitability. Panel (B) shows the same series using analysts' expectations data. ${ }^{21}$ The figures show a striking pattern: expectational errors appear to be systematic and recurring. In particular, they are consistent with the presence of excessive optimism in good times and excessive pessimism in bad times: future realized earnings growth systematically falls short of expectations when past earnings are high, and exceeds expectations when past earnings are low. ${ }^{22}$

To statistically corroborate the patterns in figure 4 , we present regressions of expectational errors on past profitability. Column (1) of table 8, panel (A), reports the results using CFO data. Column (1) of table 9, panel (A), reports the results using analyst data. In both cases, high past-year profitability is correlated with over-optimism, while low past-year profitability is correlated with over-pessimism..$^{23}$ The magnitude of the bias is large. A one standard deviation increase in past profitability is associated with a 0.6 standard deviation increase in the magnitude of CFOs' expectational errors. ${ }^{24}$ Figure 5 further illustrates these results with scatter plots of expectational errors against past profitability. It shows that the bias is present throughout the sample period, and not driven by a single outlier event. 

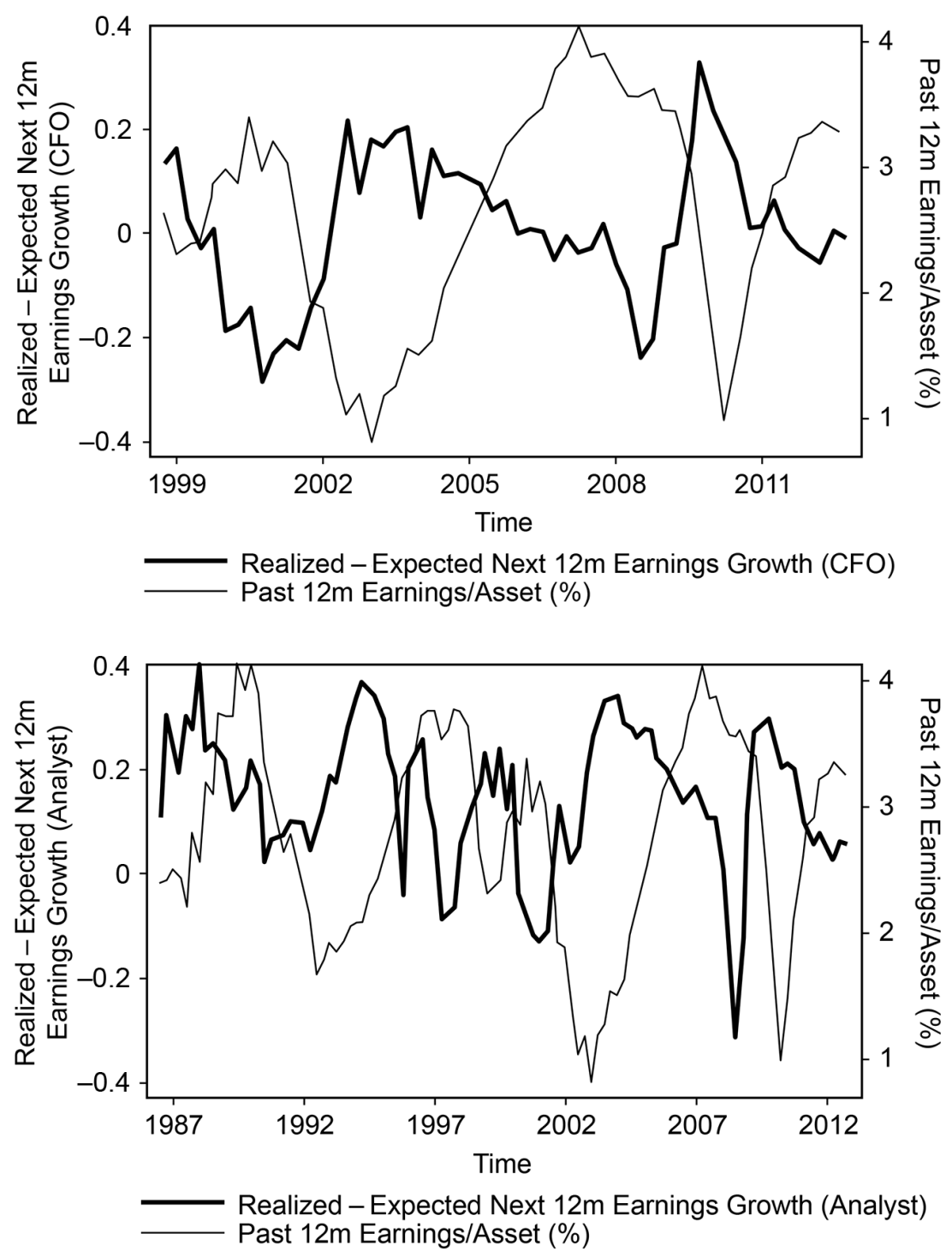

Fig. 4. Errors in earnings expectations and past profitability: Time series plots Note: The plots above show aggregate errors in earnings expectations and past 12-month corporate profitability. In both panels, the thin line is aggregate earnings over assets in the past 12 months. In panel (A), the thick line is aggregate earnings growth in the next 12 months minus aggregate CFO expectations of earnings growth in the next 12 months. In panel (B), the thick line is aggregate earnings growth in the next 12 months minus aggregate analyst expectations of earnings growth in the next 12 months. Series are linearly detrended. Frequency is quarterly. 

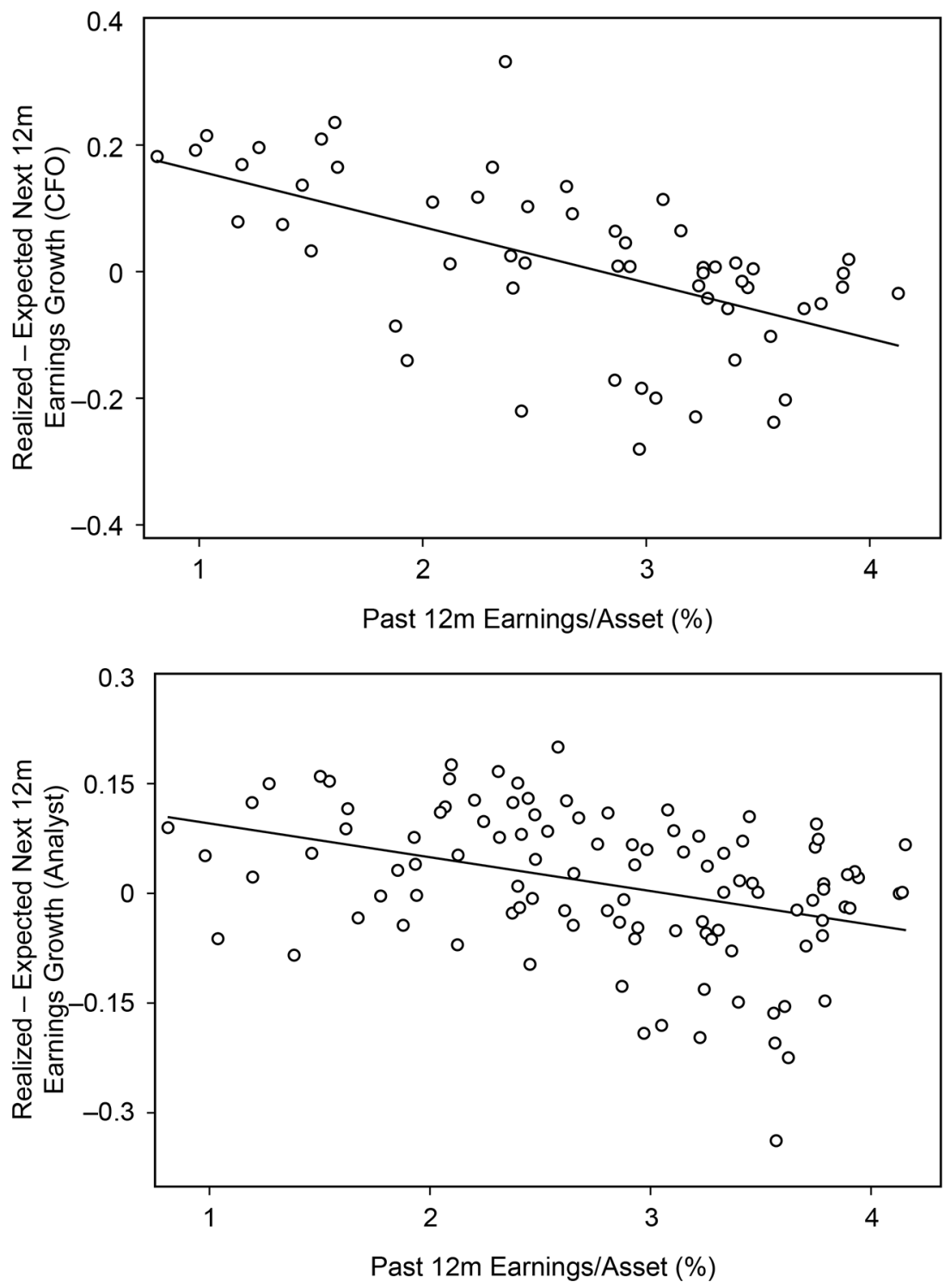

Fig. 5. Errors in earnings expectations and past profitability: Scatter plots Note: Scatter plots of aggregate errors in earnings expectations against past 12-month corporate profitability. Variables are identical to those in figure 4 . Frequency is quarterly. 
Table 8

Predicting Errors in CFO Expectations

\begin{tabular}{|c|c|c|c|c|c|c|}
\hline \multicolumn{7}{|c|}{ A. Aggregate Evidence } \\
\hline & \multicolumn{6}{|c|}{ Realized - CFO Expected Next $12 \mathrm{~m}$ Earnings Growth } \\
\hline & $(1)$ & $(2)$ & (3) & $(4)$ & (5) & (6) \\
\hline $\begin{array}{l}\text { Past } 12 \mathrm{~m} \text { earnings / } \\
\text { asset }(\%)\end{array}$ & $\begin{array}{l}-0.0881 \\
(-6.48)\end{array}$ & & $\begin{array}{l}-0.0915 \\
(-8.85)\end{array}$ & & $\begin{array}{l}-0.0882 \\
(-7.42)\end{array}$ & \\
\hline $\begin{array}{l}\text { Past } 12 \mathrm{~m} \text { GDP } \\
\text { growth }\end{array}$ & & $\begin{array}{l}-3.2999 \\
(-3.06)\end{array}$ & & $\begin{array}{l}-3.6632 \\
(-3.38)\end{array}$ & & $\begin{array}{l}-4.2078 \\
(-3.30)\end{array}$ \\
\hline VIX & & & $\begin{array}{l}-0.2552 \\
(-1.51)\end{array}$ & $\begin{array}{l}-0.3288 \\
(-1.46)\end{array}$ & & \\
\hline $\begin{array}{l}\text { Agg. stock index } \\
\text { vol. }\end{array}$ & & & & & $\begin{array}{l}-0.0089 \\
(-0.02)\end{array}$ & $\begin{array}{l}-0.4101 \\
(-1.52)\end{array}$ \\
\hline Observations & 57 & 57 & 57 & 57 & 57 & 57 \\
\hline R-squared & 0.335 & 0.225 & 0.361 & 0.266 & 0.335 & 0.269 \\
\hline
\end{tabular}

Realized - CFO Expected Next 12m Earnings Growth

\begin{tabular}{|c|c|c|c|c|c|c|}
\hline & (1) & (2) & (3) & (4) & (5) & (6) \\
\hline $\begin{array}{l}\text { Past } 12 \mathrm{~m} \text { firm } \\
\text { earnings / asset (\%) }\end{array}$ & $\begin{array}{l}-0.0511 \\
(-5.14)\end{array}$ & & $\begin{array}{l}-0.0500 \\
(-5.22)\end{array}$ & & $\begin{array}{l}-0.0324 \\
(-3.40)\end{array}$ & $\begin{array}{l}-0.0353 \\
(-3.56)\end{array}$ \\
\hline $\begin{array}{l}\text { Past } 12 \mathrm{~m} \text { GDP } \\
\text { growth }\end{array}$ & & $\begin{array}{l}-4.1472 \\
(-2.44)\end{array}$ & & $\begin{array}{l}-2.811 \\
(-1.75)\end{array}$ & & \\
\hline Firm stock vol. & & & $\begin{array}{l}0.3959 \\
(1.74)\end{array}$ & $\begin{array}{l}0.2229 \\
(0.94)\end{array}$ & & $\begin{array}{l}0.5299 \\
(1.13)\end{array}$ \\
\hline $\begin{array}{l}\text { Firm fixed effects } \\
\text { Time fixed effects }\end{array}$ & $\begin{array}{l}\text { Y } \\
\text { No }\end{array}$ & Y & $\mathrm{Y}$ & $\mathrm{Y}$ & $\begin{array}{l}\text { Y } \\
\text { Yes }\end{array}$ & $\mathrm{Y}$ \\
\hline Observations & 606 & 651 & 594 & 638 & 606 & 594 \\
\hline R-squared & 0.082 & 0.032 & 0.103 & 0.033 & 0.037 & 0.050 \\
\hline Number of firms & 142 & 147 & 139 & 144 & 142 & 139 \\
\hline
\end{tabular}

Note: Quarterly regressions of errors in CFO expectations of next 12-months earnings growth on past profitability and past economic conditions. In panel (A), the dependent variable is aggregate earnings growth in the next 12 months minus aggregate CFO expectations of earnings growth in the next 12 months. Independent variables include aggregate earnings/asset and GDP growth in the four quarters prior to quarter $t-1$. Controls include VIX by the end of quarter $t-1$ and aggregate stock volatility as of quarter $t-1$. In panel (B), the dependent variable is firm-level earnings growth in the next 12 months minus firm $\mathrm{CFO}$ expectations of earnings growth in the next 12 months. Independent variables include firm-level earnings/asset in the four quarters prior to quarter $t-1$, and volatility of firm stock in quarter $t-1$. A constant is included but not reported. In panel (A), standard errors are Newey-West with twelve lags. In panel (B), standard errors are clustered by firm. R-squared excludes firm and time fixed effects. $t$-statistics in parentheses. 
Table 9

Predicting Errors in Analyst Expectations

\begin{tabular}{|c|c|c|c|c|c|c|}
\hline \multicolumn{7}{|c|}{ A. Aggregate Evidence } \\
\hline & \multicolumn{6}{|c|}{ Realized - Analyst Expected Next 12m Earnings Growth } \\
\hline & (1) & (2) & (3) & $(4)$ & (5) & (6) \\
\hline $\begin{array}{l}\text { Past } 12 \mathrm{~m} \text { earnings / } \\
\text { asset }(\%)\end{array}$ & $\begin{array}{l}-0.0456 \\
(-3.68)\end{array}$ & & $\begin{array}{l}-0.0550 \\
(-6.16)\end{array}$ & & $\begin{array}{l}-0.0467 \\
(-3.76)\end{array}$ & \\
\hline $\begin{array}{l}\text { Past } 12 \mathrm{~m} \text { GDP } \\
\text { growth }\end{array}$ & & $\begin{array}{l}-1.3940 \\
(-1.70)\end{array}$ & & $\begin{array}{l}-1.1277 \\
(-1.67)\end{array}$ & & $\begin{array}{l}-1.6171 \\
(-1.64)\end{array}$ \\
\hline VIX & & & $\begin{array}{l}-0.2904 \\
(-1.73)\end{array}$ & $\begin{array}{l}-0.3260 \\
(-2.52)\end{array}$ & & \\
\hline $\begin{array}{l}\text { Agg. stock index } \\
\text { vol. }\end{array}$ & & & & & $\begin{array}{l}-0.0991 \\
(-0.47)\end{array}$ & $\begin{array}{l}-0.1116 \\
(-0.51)\end{array}$ \\
\hline Observations & 106 & 112 & 91 & 91 & 106 & 112 \\
\hline R-squared & 0.144 & 0.057 & 0.245 & 0.078 & 0.150 & 0.062 \\
\hline \multicolumn{7}{|c|}{ B. Firm-Level Evidence } \\
\hline & \multicolumn{6}{|c|}{ Realized - Analyst Expected Next 12m Earnings Growth } \\
\hline & (1) & (2) & (3) & (4) & (5) & (6) \\
\hline $\begin{array}{l}\text { Past } 12 \mathrm{~m} \text { firm } \\
\text { earnings / asset (\%) }\end{array}$ & $\begin{array}{l}-0.0080 \\
(-7.43)\end{array}$ & & $\begin{array}{l}-0.0081 \\
(-7.36)\end{array}$ & & $\begin{array}{l}-0.0061 \\
(-6.71)\end{array}$ & $\begin{array}{l}-0.0062 \\
(-6.63)\end{array}$ \\
\hline $\begin{array}{l}\text { Past } 12 \mathrm{~m} \text { GDP } \\
\text { growth }\end{array}$ & & $\begin{array}{l}-1.6167 \\
(-3.83)\end{array}$ & & $\begin{array}{l}-1.6235 \\
(-3.72)\end{array}$ & & \\
\hline Firm stock vol. & & & $\begin{array}{l}0.0158 \\
(0.26)\end{array}$ & $\begin{array}{l}-0.0256 \\
(-0.50)\end{array}$ & & $\begin{array}{l}-0.0123 \\
(-0.40)\end{array}$ \\
\hline Firm fixed effects & Y & Y & Y & Y & Y & Y \\
\hline Time fixed effects & \multicolumn{4}{|c|}{ No } & \multicolumn{2}{|c|}{ Yes } \\
\hline Observations & 103,930 & 123,430 & 100,451 & 115,120 & 103,930 & 100,451 \\
\hline R-squared & 0.005 & 0.004 & 0.006 & 0.004 & 0.003 & 0.003 \\
\hline Number of firms & 4,432 & 5,080 & 4,227 & 4,606 & 4,432 & 4,227 \\
\hline
\end{tabular}

Note: Quarterly regressions of errors in analyst expectations of next 12 months earnings growth on past profitability and past economic conditions. In panel (A), the dependent variable is aggregate earnings growth in the next 12 months minus aggregate analyst expectations of earnings growth in the next 12 months. In panel (B), the dependent variable is firm-level earnings growth in the next 12 months minus analyst expectations of earnings growth in the next 12 months. All control variables are the same as in table 8 . A linear time trend is included. A constant is included but not reported. In panel (A), standard errors are Newey-West with 12 lags. In panel (B), standard errors are clustered by firm and time. R-squared excludes firm and time fixed effects. $t$-statistics in parentheses. 
Column (2) in panel (A) of tables 8 and 9 correlate expectational errors with past GDP growth to check whether over-optimism and overpessimism are predictable by aggregate economic performance. We also find higher past GDP growth is associated with over-optimism, and vice versa (although the statistical significance on past GDP growth is a bit lower). ${ }^{25}$

One way to interpret these results is that expectations depart from rationality in the direction of being extrapolative: when CFOs or analysts observe good or bad earnings realization, they think that similar realization persists into the future and fail to correct for mean reversion. To illustrate, we separately examine, and then compare, how actual future earnings growth and expected future earnings growth correlate with past year profitability. When past year earnings over assets increase by 1 percentage point, actual earnings growth in the next 12 months on average slows down by 0.12 . However, CFOs only expect next 12 -month earnings growth to slow down by about 0.03 . The difference between the true and perceived reversion corresponds to the coefficient of -0.09 in panel (A), column (1).

We find very similar results at the firm level. In table 8, panel (B), we examine expectational errors of individual CFOs. We use past-year firm profitability and GDP growth as main predictors of expectational errors. Consistent with previous evidence at the aggregate level, expectational errors of individual CFOs are also strongly correlated with firm profitability and general economic conditions, in a way that appears to be extrapolative. At the firm level, as past-year earnings over assets increase by 1 percentage point, next 12 -month earnings growth tends to slow down by 0.06 , whereas CFOs only expect it to slow down by 0.01 on average. This results in a difference of -0.05 , as shown by panel (B), column (1).

Note that profitability is likely to be heterogeneous across firms, and the normal level of earnings over assets can be quite different for established firms than for young firms, and for firms in different industries (this can be of particular concern when we turn to the analyst sample, which is much more heterogeneous than the CFO survey sample). To account for firm-specific average profitability, we include firm fixed effects. In the setting of error predictability regressions, strict exogeneity required by traditional fixed effect estimators may not be satisfied. Under the null of rational expectations, only sequential exogeneity will be satisfied. We perform robustness checks using dynamic panel estimators as in Arellano and Bover (1995), ${ }^{26}$ and results are very similar. For 
standard errors in firm-level tests, we always cluster by firm and we double cluster by both firm and time whenever the length of the panel makes it appropriate to do so.

In columns (5) and (6) of table 8, panel (B), we report results adding time fixed effects, which helps us assess the extent to which expectational errors load on the idiosyncratic component of firm profitability. By teasing out aggregate shocks, time fixed effects may also attenuate issues in rational expectations tests when the panel is relatively short (this can be a concern with the CFO panel, which spans seven years and 28 quarters, and is less of a concern with the analyst panel, which covers 28 years and 112 quarters). ${ }^{27}$ We find that CFOs seem to significantly extrapolate the idiosyncratic component of past profitability. Together, results in table 8 show that the extrapolative structure of CFO expectations appears pervasive. Past year economic conditions, and both the aggregate and the idiosyncratic component of firm profitability, are all correlated with CFOs' expectational errors.

In table 9 , we perform the same set of tests as in table 8 using analyst expectations. The results are similar: analysts also tend to overestimate next 12-month earnings growth when past-year firm profitability is high and when past-year economic conditions are favorable, and underestimate future earnings growth when the past year is rough.

At first glance, the patterns in $\mathrm{CFO}$ and analyst expectations are quite consistent with extrapolative biases observed in financial markets. As shown by Greenwood and Shleifer (2014), many market participants-including both individual and institutional investors, as well as CFOs surveyed by Graham and Harvey-tend to extrapolate stock price trends formed in the past year. They generally think that the past year's trend would continue, whereas in reality it tends to revert. As explained in Section II and shown in figure 1, investors tend to become significantly more optimistic about stock market performance in the next 12 months when market returns in the past year are high, and vice versa (figure 1 , panel [A]). Corporate CFOs are equally extrapolative in their expectations about next 12-month market returns (figure 1, panel [B]). Piazzesi, Salomao, and Schneider (2015) also find that bond market investors tend to perceive interest rate trends to be more persistent than they are. The extrapolative tendency in expectations formation resonates with the well-known representativeness bias in human judgment (Kahneman and Tversky 1972; Tversky and Kahneman 1974), which can lead people to view events similar to re- 
cent experiences as typical and likely, and to discount scenarios that are different from the prevailing situation (Gennaioli, Shleifer, and Vishny 2015).

While our evidence is consistent with extrapolation in earnings expectations, other factors may contribute to apparent deviations from rationality. In the following, we address a set of possible concerns.

\section{Misinterpretation of Survey Question}

First, we would like to make sure that the apparent errors in expectations do not simply reflect respondents misinterpreting the survey question. This could be a concern for $\mathrm{CFO}$ expectations, as $\mathrm{CFO}$ are directly asked to provide forecasts of earnings growth in the next 12 months, and there could be alternative definitions of next 12-month earnings growth. This is not an issue, however, for analyst expectations, since analysts provide forecasts of total earnings in specific future quarters, and we compute the implied expected next 12-month earnings growth by combining their forecasts with actual past earnings; we then compare this variable to realizations to test forecast accuracy. ${ }^{28}$

To be specific, while the CFO survey asks about earnings growth in the next 12 months defined as the percentage change of earnings in the next 12 months relative to earnings in the past 12 months, respondents could instead provide expectations about earnings 12 months from now relative to current earnings. If this were true, when we compare survey responses to actual earnings growth in the next 12 months-which we follow the survey question to define as earnings in the next 12 months over earnings in the past 12 months-we might get spurious errors. For clarity of exposition, we denote next twelve month earnings growth defined by the survey as

$\Delta$ Earnings $_{t}=$ earnings in the next 12 months / earnings in the past 12 months.

We denote the alternative interpretation as $\Delta$ Earnings $_{t}^{\text {alt }}=$ earnings 12 months from now / current earnings, and we denote $\mathrm{CFO}$ responses as $\mathrm{E}_{t}^{\mathrm{CFO}}$.

We provide two checks to show that respondents do not appear to misinterpret the question. First, figure 2 shows that CFO responses and analyst expectations are quite consistent with each other when analyst expectations are computed following the survey definition of next 12 -month earnings growth. However, if we instead compute analyst ex- 
pectations of earnings four quarters from now relative to current earnings, the result looks much more different from CFO responses. Second and more importantly, if we compute actual earnings four quarters from now relative to current earnings (namely $\Delta$ Earnings $^{\text {alt }}$ ) and compare it to $\mathrm{CFO}$ responses, then CFOs would appear much less accurate in their forecasts. In particular, while aggregate $\mathrm{CFO}$ responses are 0.54 correlated with $\Delta$ Earnings $_{t}$, they are only 0.1 correlated with $\Delta$ Earnings $_{t}^{\text {alt }}$. In addition, if we construct expectational error as $\Delta$ Earnings $s_{t}^{\text {alt }}-\mathrm{E}_{t}^{\mathrm{CFO}}$, this variable is still predictable by past 12 -month profitability. ${ }^{29}$ Across all robustness checks, we find actual CFO responses are closest to the survey's intended definition of next 12-month earnings growth, and by comparing CFO responses to $\Delta$ Earnings $_{t}$ we obtain the most conservative results with respect to deviations from rationality.

\section{Asymmetric Loss Functions}

A common concern with forecast data is that respondents might have asymmetric loss functions that cause them to report expectations that deviate from their objective views. For instance, analysts may want to please firm management and release upward-biased forecasts (Lim 2001). In the case of CFOs, reputational or other "publicity" considerations are unlikely to be at play, as individual responses in the CFO survey are never published. From this perspective, CFOs should not have much incentive to bias their responses for signaling purposes.

The main challenge for explanations with asymmetric loss functions is to account for the time-varying nature of expectational errors. Commonly used specifications of asymmetric loss functions (such as the LINEX function, and the Lin-Lin function under certain assumptions) generally yield optimal forecasts that are linear in objective expectations and conditional variance of the forecast variable. Given that conditional volatility of earnings tends to be higher in bad times, for asymmetric loss functions to generate more "pessimism" in bad times and more "optimism" in good times, overpredicting must be more costly than underpredicting. In this case, however, we would expect reported expectations to be consistently biased downward (with the magnitude increasing in the size of the conditional variance), which is not the case for either CFOs or analysts. ${ }^{30}$

While we do not find compelling reasons why asymmetric loss functions can drive our results, we nevertheless perform a set of robustness checks. In table 8 and table 9 we control for various proxies of volatility, 
including the VIX index and recent stock price volatility. We find that the volatility terms do not enter significantly, and our main results are unchanged. This evidence suggests that it is the level of past earnings that affects systematic forecast errors, whereas uncertainty plays a minor role.

\section{Risk-Neutral Probability Weighting}

Another possible concern is that CFOs might be reporting expectations not under physical probabilities, but under certain types of risk-neutral probabilities. Reporting expectations of future earnings growth is distinctively different from pricing, or calculation of expected returns of an asset. In the context of pricing, future cash flows may be discounted using a stochastic discount factor, or correspondingly, weighted by risk-neutral probabilities. In the context of forecasting future earnings growth, it is not plausible that any discounting is present and that there is an associated stochastic discount factor from optimizing theories. ${ }^{31}$ It is possible that certain scenarios might be more salient in people's minds that lead to distorted probability weighting, but this explanation would fall into the category of cognitive biases and nonrational expectations (Bordalo, Gennaioli, and Shleifer 2012).

\section{Conditional Expectations versus other Conditional Moments}

Properties of rational expectations tests hold under the assumption that respondents provide conditional expectations of variables of interest. One concern could be that respondents might be reporting conditional medians, conditional modes, or other conditional moments instead of conditional expectations. For medians in particular, we can perform robustness checks with least absolute deviations regressions, which yield similar results to ordinary least squares (OLS). More generally, for this type of problem to affect our results, it has to be that following high past profitability the moment people report is greater than the conditional mean, and vice versa. We check the distribution of future-earnings growth conditioning on past profitability, and do not find any evidence that conditional medians and modes follow this pattern (appendix $\mathrm{C}$, figure $\mathrm{C} 1$, plots the distribution of next 12-month earnings growth given a certain level of past profitability). Although we are not able to rule out the possibility that respondents report some other moments that happen to behave this way, it is not obvious what these moments 
could be and why respondents across different groups all prefer to use them. Certainly, more precise elicitation of expectations will be highly beneficial, as stressed by Manski (2004), but within available data, we do not find compelling evidence that the observed overoptimism and overpessimism could be explained by respondents reporting alternative conditional moments.

\section{Information Rigidities and Rational Inattention}

Finally, recent research points to other frictions that can affect expectations formation, including information rigidities (Mankiw and Reis 2002) and inattention (Sims 2003, 2010). While these frictions are important in many economic settings, they may not be natural explanations for the extrapolative errors in CFOs' and analysts' earnings expectations. Although managers and analysts may not pay full attention to information such as GDP growth or inflation, it is not quite plausible that past firm earnings are not in their information set, or that such information just slips their minds. After all, earnings are quite important for firms, as well as for management compensation. Similarly, analysts, who are designated to forecast future earnings and whose performance is judged in part by the accuracy of their forecasts, are also unlikely to be inattentive to earnings. ${ }^{32}$

In sum, our evidence points to systematic extrapolative biases in CFO and analyst expectations. While we cannot definitively rule out that some combinations of limited sample span, measurement error, and more complicated versions of informational frictions and loss functions could account for some these results, extrapolation stands out as the most parsimonious explanation. The findings also echo accumulating evidence in finance that extrapolation arises in many settings, and appears to be a common psychological tendency in expectations formation.

\section{Summary and Implications}

Our analysis of data on earnings expectations and investment yields two basic conclusions. First, expectations data appear to be extremely helpful in understanding corporate investment plans and actual investment, more so than some traditional measures of determinants of investment. Second, several empirical tests appear to reject the rational expectations benchmark, pointing to the extrapolative nature of expectations. 
At a minimum, the evidence endorses Manski's (2004) call for collecting and using expectations data to evaluate economic theories. Our project would not have been possible without John Graham and Campbell Harvey's CFO data. But as is often the case with a preliminary analysis and with limited data, there are many questions that we cannot address with the data we have.

Yet even our preliminary results suggest some directions for future work. The finding that expectations do so well in accounting for investment plans and actual investment suggests a possible strategy for reviving the $q$-theory of investment. It is well known that the standard $q$-theory investment equation does not work well in levels, and requires first differencing to have some explanatory power (Barro 1990). Our findings, along with earlier research by Cummins et al. (2006), suggest that the problem may be not with the $q$-theory itself, but with the stock market-based measures of Tobin's $q$. This is not entirely surprising in light of the growing evidence of noisiness and nonfundamental fluctuations of stock prices (Shiller 1981; Morck et al. 1990). A measure of investment opportunities based on actual expectations of corporate managers does much better in explaining investment, regardless of whether the equation is estimated in levels or in changes. A constructive way to revive $q$-theory is to start with data on expectations, and not on stock market valuations.

The second direction suggested by our evidence, as well as by the previous work, is the need to construct plausible models of expectations. In macroeconomics, in particular, such models have to come to grips with some version of the Lucas critique, which was applied initially precisely to Cagan's and other models of adaptive expectations. In our view, market participants might be backward looking and extrapolative to some extent, but surely they also have some ideas of how the economy evolves that are forward looking. Developing models along these lines is an open problem. Our own approach has been to use psychological models of expectations that incorporate both forward- and backward-looking elements (e.g., Bordalo, Gennaioli, and Shleifer 2013; Gennaioli et al. 2015), but this research is still some way from being ready for a macroeconomic model.

The larger question, of course, is whether expectations have a significant role to play in macroeconomic modeling. A recent literature in macroeconomics considers expectations "shocks," and discusses the extent to which they can contribute to economic fluctuations (Beaudry and Portier 2004; Angeletos and La'O 2010; Lorenzoni 2009; Barsky and 
Sims 2012; Angeletos and La'O 2013; Levchenko and Pandalai-Nayar 2015). Our perspective is quite different; the evidence suggests that expectations have a fairly precise extrapolative structure, and do not just vibrate randomly. They are not noise; there is a systematic pattern of errors. Moreover, we believe-and our evidence seems supportive of this belief-that market participants make common expectational errors. Here we show that these errors are common to analysts and CFOs; we suspect the beliefs of policymakers are highly correlated with those of market participants. It seems to us that, as a consequence, plausible models would consider common errors among many economic agents, which therefore would have potential aggregate effects.

The final question is whether such errors can account for some part of macroeconomic fluctuations, such as aggregate overbuilding in important sectors like the housing market, or prolonged recessions with a lack of corporate investment and hiring. Our data have limitations for quantifying how the erroneous component of expectations affects investment, since the rational level of investment is not observable, but has to be inferred from making additional assumptions about the decision makers' environment and information, which requires extra discretion. It is a further step still that a common error translates into aggregate investment distortions. We leave this to future work.

\section{Endnotes}

We are deeply grateful to John Graham and Campbell Harvey for providing data from the CFO survey, and to Joy Tianjiao Tong for helping us to access the data. We thank our discussants Monika Piazzesi and Chris Sims, as well as Gary Chamberlain, Martin Eichenbaum, Carlo Favero, Robin Greenwood, Luigi Guiso, Sam Hanson, Chen Lian, Jonathan Parker, Fabiano Schivardi, Jim Stock, and Mirko Wiederholt for useful suggestions. We also thank Yang You for research assistance. For acknowledgments, sources of research support, and disclosure of the authors' material financial relationships, if any, please see http://www.nber.org/chapters/c13589.ack.

1. See the online appendix at http://www.nber.org/data-appendix/c13589/appendix.pdf.

2. Graham and Harvey (2011) provide a detailed description of the survey. Historical questionnaires are available at http:/ / www.cfosurvey.org.

3. The number of observations in our firm-level regressions can be smaller because some respondents do not answer all questions.

4. We performed detailed checks and verified that IBES actual earnings indeed appear to be closest to forecasts by managers and analysts, in terms of accounting treatment, magnitude, variance, and variation over time.

5 . The assumption of risk neutrality and constant discount rate is for simplicity of exposition. The framework can be extended to incorporate time-varying discount rates, as derived in Lettau and Ludvigson (2002). In our empirical analysis in Section IV.B and Section IV.C, we will explicitly consider time-varying discount rates.

6. See http://www.nber.org/data-appendix/c13589/appendix.pdf. 
7. Plans are particularly helpful in the context of our data, where we observe forward-looking expectations once a quarter rather than once a year. With lags in investment implementation, it is unlikely that expectations in a given quarter will be immediately reflected in capital spending in the same quarter, or even fully incorporated into capital spending in the next quarter. In comparison, investment plans would be more responsive to contemporaneous expectations. When managers become more optimistic, they would revise their plans upward. As plans get implemented over time, the impact on actual capital expenditures can show up with some delay. For this reason, it is more straightforward to start testing the impact of expectations by looking at investment plans.

8. See http://www.nber.org/data-appendix/c13589/appendix.pdf.

9. One might also consider an alternative approximation of equation (1) of the following form $I_{t-1} / K_{t-1} \approx \hat{\theta}_{0}+\hat{\theta}_{1} \mathbb{E}_{t}\left(\Pi_{t}\right) / K_{t}$ where $I_{t-1}$ denotes realized investment in the past 12 months, and $\mathbb{E}_{t}\left(\Pi_{t}\right)$, as before, is current expectations of earnings in the next 12 months. This approximation is reasonable under two conditions. As in the case of equation (2), it should be that expectations over future earnings are stable. Moreover, it has to be that respondents received little information and barely updated their beliefs in the past 12 months, so that current expectations about next-12-month earnings, namely $\mathbb{E}_{t}\left(\Pi_{t}\right)$, is close to expectations four quarters ago about earnings over the same period, namely $\mathbb{E}_{t-1}\left(\Pi_{t}\right)$. We find this approximation to be less tenable for several reasons. First, from time to time new information arrives over a 12-month period that has a significant impact on people's beliefs. (This can happen even if earnings processes are highly persistent, for example, if it is a random walk.) Second, given implementation lags in real-world investment activities, actual capital spending over a 12 -month period tends to be particularly influenced by decisions made at the beginning of the period. As a result, realized capital spending in year $t-1, I_{t-1}$, may not be well explained by expectations at the end of year $t-1$. In light of these observations, we use the approximation in equation (2) in the rest of our analysis.

10. We check the autocorrelation structure of the errors: autocorrelations are mostly limited to the first four lags, due to the overlapping structure of our data; autocorrelations after four lags are minimal. Our empirical results are not sensitive to alternative choices of Newey-West lags.

11. At the aggregate level, during the period where we have CFO expectations data, the standard deviation of planned investment growth is about 0.05 , and the standard deviation of earnings growth expectations is $0.07 .0 .07 * 0.6 / 0.05=0.8$.

12. Due to lags in investment implementation it is also possible that, at a given quarter, part of the capital spending that firms expect to make in the next 12 months are determined by decisions made, for example, in the last quarter, and therefore affected by expectations then. In aggregate data, we can include lagged expectations, in which case current expectations and past expectations with two lags are significant, and jointly highly significant. Unfortunately, it is difficult to include lagged expectations in firm-level tests, since we do not always observe individual firms continuously. Therefore, in the baseline specifications we include only current expectations.

13. We thank our discussant Chris Sims for the suggestion of a more careful examination of the role of expectational shocks, as well as the feedback among different variables, through VARs. To the extent that expectations experience a meaningful amount of exogenous shocks above and beyond reactions to observable information (so that what appear to be expectational shocks is not simply measurement error), studying expectational shocks may improve identification. It would also be ideal to have a longer time series (we currently only have 57 quarterly observations of CFO expectations and 112 quarterly observations of analyst expectations) to reliably estimate the dynamic relationships. In our first-step analysis, we study the impact of measured expectations as a whole to show the basic core facts. The investigation of expectational shocks is an interesting issue that we leave to future research.

14. As illustrated in Section IV, proxies of $q$ are supposed to represent the $q$ model precisely, whereas survey data can only represent it approximately. Thus it may not be surprising that $q$ proxies remain significant in regressions that include survey expectations. 
15. Our results also resonate with recent findings by Sharpe and Suarez (2014) and Kothari, Lewellen, and Warner (2014) that changes in discount rates and user cost of capital have limited impact on investment, and that corporations appear to apply constant hurdle rates in making investment decisions.

16. Stambaugh bias arises when predictor variables are relatively persistent, and innovations in predictor variables and outcome variables are correlated. In theory, investment should be high when discount rates are low. Thus we would expect a negative coefficient on discount rates. To the extent that innovations in investment and discount rates are negatively correlated, Stambaugh bias will be upward, pushing the coefficient on discount rates closer to or above zero.

17. The appendix can be found at http://www.nber.org/data-appendix/c13589/appendix.pdf.

18. Here we use past net income rather than pro forma earnings to be conservative, since the actual internal resources that firms gain from cash flows need to deduct most of the extraordinary items. Results using either form of profit metric to control for past cash flows are very similar.

19. To the extent that strict exogeneity may not be satisfied, fixed effect estimators may be biased in finite sample. In our context, it will bias the coefficient on earnings expectations downwards. Regressions without fixed effects and those using dynamic panel methods show that the bias does not appear to be very important. Given that we do not always continuously observe individual firms in the CFO sample, it is difficult to take first differences and use lagged instruments. Instead, for dynamic panel estimations we apply the forward orthogonal deviations (FOD) transformation as in Arellano and Bover (1995).

20. Figure 2 uses aggregate investment as measured by private nonresidential fixed investment from NIPA. We can alternatively use capital expenditures data from Flow of Funds or Compustat, and results are very similar.

21. The errors are computed as aggregate realized next-12-month earnings growth aggregate CFO (analyst) expectations of next-12-month earnings growth. As we cannot identify the full set of firms that answer the CFO survey in each quarter, this sample may differ from the full sample with which we use to compute aggregate realized earnings growth. For robustness, to make sure that aggregate earnings growth patterns are representative, we alternatively compute aggregate earnings growth by taking the mean or median earnings growth in each quarter. We find this makes very little difference, and we get similar empirical results in all cases.

22. Note that earnings in quarter $t$ are typically announced several weeks into quarter $t+1$, thus we use earnings from quarter $t-5$ through $t-2$ to compute past-year profitability, so as to ensure that all information in the predictor variable is strictly in the information set of CFOs and analysts when they make forecasts in quarter $t$.

23. To address concerns that past-year profitability is relatively persistent (though it is much less persistent than variables like discount rate proxies), we present bootstrap biasadjusted results in appendix $\mathrm{C}$, table $\mathrm{C}$. We find very similar results. (The appendix is at http://www.nber.org/data-appendix/c13589/appendix.pdf.)

24. During the period where we have CFO expectations, the standard deviation of past-year earnings/asset is 0.88 , and the standard deviation of expectational errors is 0.13. $0.88 * 0.09 / 0.13=0.6$.

25. To be conservative, past-12-month GDP growth also ends at quarter $\mathrm{t}-2$ because GDP is reported with a lag.

26. The forward orthogonal deviations (FOD) transformation studied by Arellano and Bover (1995) is most helpful as our CFO panel contains gaps.

27. One possible concern is that time fixed effects may not completely tease out aggregate shocks if different firms are affected differently by an aggregate shock. For this to affect our results, it has to be that firms that happen to have a profitable past year are hit harder by an adverse aggregate shock, and vice versa. We do not find very compelling evidence for this concern.

28. In other words, in the case of analysts, we compute expected next-12-month earnings growth $=$ analyst forecasts of earnings in the next 12 months/actual earnings in the past 
12 months, and compare it to realized next-12-month earnings growth $=$ actual earnings in the next 12 months/actual earnings in the past 12 months. We can alternatively normalize analyst forecasts of next-12-month earnings by current assets, and results are very similar.

29. Relatedly, to test the accuracy of earnings expectations, it is highly important that we use the same earnings measure as CFOs and analysts. As mentioned in Section III, we use pro forma actual earnings from IBES instead of GAAP earnings. The earnings measures we use are the ones CFOs report in earnings announcements and the ones analysts generally aim to match. In addition, we check that they are closest to CFO and analyst forecasts in terms of magnitude, variance, and variation over time. When compared to GAAP earnings, CFO and analyst expectations appear to be much less accurate, and error predictability remains.

30. One might also consider alternative scenarios where CFOs and analysts have timevarying loss functions. For this to explain our results, it has to be that people prefer to underpredict in bad times and to overpredict in good times. We do not find compelling reasons why it is optimal to follow this strategy.

31. In addition, to the extent that high earnings are associated with low SDF (i.e., in general, earnings are high in good states), earnings growth under risk-neutral probabilities (which is always a well-defined mathematical object, though its economic interpretation may be unclear) will be consistently lower than earnings growth under physical probabilities. We find no evidence that either CFOs or analysts appear to be persistently pessimistic.

32. We also test the extent to which expectational errors are predictable by the forecast itself or by past forecasts. We find that higher forecasts are associated with lessthan-expected actuals, and vice versa. However, this result could be especially susceptible to the influence of measurement errors, as any random measurement error of the forecast would mechanically affect expectational errors. Thus we interpret it with extra caution.

\section{References}

Abarbanell, Jeffery S. 1991. "Do Analysts' Earnings Forecasts Incorporate Information in Prior Stock Price Changes?" Journal of Accounting and Economics 14:147-65.

Amromin, Gene, and Steven A. Sharpe. 2014. "From the Horse's Mouth: Economic Conditions and Investor Expectations of Risk and Return" Management Science 60 (4): 845-866.

Ang, Andrew, Geert Bekaert, and Min Wei. 2007. "Do Macro Variables, Asset Markets, or Surveys Forecast Inflation Better?" Journal of Monetary Economics 54 (4): 1163-212.

Angeletos, George-Marios, and Jennifer La'O. 2010. "Noisy Business Cycles." NBER Macroeconomics Annual 2009, vol. 24, ed. Daron Acemoglu, Kenneth Rogoff, and Michael Woodford, 319-78. Chicago: University of Chicago Press. . 2013. "Sentiments." Econometrica 81 (2): 739-79.

Arellano, Manuel, and Olympia Bover. 1995. "Another Look at the Instrumental Variable Estimation of Error-Components Models." Journal of Econometrics 68 (1): 29-51.

Arif, Salman, and Charles M.C. Lee. 2014. "Aggregate Investment and Investor Sentiment." Review of Financial Studies 27 (11): 3241-79.

Bacchetta, Philippe, Elmar Mertens, and Eric Van Wincoop. 2009. "Predictability in Financial Markets: What Do Survey Expectations Tell Us?" Journal of International Money and Finance 28 (3): 406-26.

Baker, Malcolm, Ryan Taliaferro, and Jeffrey Wurgler. 2006. "Predicting Returns 
with Managerial Decision Variables: Is There a Small-Sample Bias?" Journal of Finance 61 (4): 1711-30.

Baker, Scott R., Nicholas Bloom, and Steven J. Davis. 2015. “Measuring Economic Policy Uncertainty." NBER Working Paper no. 21633, Cambridge, MA.

Bansal, Ravi, Dana Kiku, Ivan Shaliastovich, and Amir Yaron. 2014. "Volatility, the Macroeconomy, and Asset Prices." Journal of Finance 69 (6): 2471-511.

Barro, Robert J. 1990. "The Stock Market and Investment." Review of Financial Studies 3 (1): 115-31.

Barsky, Robert B., and Eric R. Sims. 2012. "Information, Animal Spirits, and the Meaning of Innovations in Consumer Confidence." American Economic Review 102 (4): 1343-77.

Beaudry, Paul, and Franck Portier. 2004. "An Exploration into Pigou's Theory of Cycles." Journal of Monetary Economics 51 (6): 1183-216.

Ben-David, Itzhak, John R. Graham, and Campbell R. Harvey. 2013. “Managerial Miscalibration." Quarterly Journal of Economics 128 (4): 1547-84.

Bhattacharya, Nilabhra, Ervin L. Black, Theodore E. Christensen, and Chad R. Larson. 2003. "Assessing the Relative Informativeness and Permanence of Pro Forma Earnings and GAAP Operating Earnings." Journal of Accounting and Economics 36 (1): 285-319.

Bloom, Nicholas. 2009. "The Impact of Uncertainty Shocks." Econometrica 77 (3): 623-85.

Bloom, Nick, Stephen Bond, and John Van Reenen. 2007. "Uncertainty and Investment Dynamics." Review of Economic Studies 74 (2): 391-415.

Bordalo, Pedro, Nicola Gennaioli, and Andrei Shleifer. 2012. "Salience Theory of Choice under Risk." Quarterly Journal of Economics 127 (3): 1243-85.

623-28.

Bradshaw, Mark T., and Richard G. Sloan. 2002. "GAAP versus the Street: An Empirical Assessment of Two Alternative Definitions of Earnings." Journal of Accounting Research 40 (1): 41-66.

Burnside, Craig, Martin Eichenbaum, and Sergio Rebelo. 2015. “Understanding Booms and Busts in Housing Markets." Working paper, Northwestern University. http:/ / www.kellogg.northwestern.edu/faculty/rebelo/htm/Booms -busts.pdf.

Campbell, John Y., and John H. Cochrane. 1999. "By Force of Habit: A ConsumptionBased Explanation of Aggregate Stock Market Behavior." Journal of Political Economy 107 (2): 205-51.

Campbell, John Y., and Robert J. Shiller. 1987. "Cointegration and Tests of Present Value Models." Journal of Political Economy 95 (5): 1062-88.

- 1988. "Stock Prices, Earnings, and Expected Dividends." Journal of Finance 43 (3): 661-76.

Cochrane, John H. 1991. "Production-Based Asset Pricing and the Link between Stock Returns and Economic Fluctuations." Journal of Finance 46 (1): 209-37.

- 2011. "Presidential Address: Discount Rates." Journal of Finance 66 (4): 1047-108.

Coibion, Olivier, and Yuriy Gorodnichenko. 2012. "What Can Survey Forecasts Tell Us about Information Rigidities?" Journal of Political Economy 120 (1): 116-59.

- 2015. "Information Rigidity and the Expectations Formation Process: A Simple Framework and New Facts." American Economic Review 105 (8): $2644-78$. Cummins, Jason G., Kevin A. Hassett, and Stephen D. Oliner. 2006. “Investment 
Behavior, Observable Expectations, and Internal Funds." American Economic Review 96 (3): 796-810.

Cutler, David M., James M. Poterba, and Lawrence H. Summers. 1990. “Speculative Dynamics and the Role of Feedback Traders." American Economic Review 80 (2): 63-68.

De Bondt, Werner, and Richard H. Thaler. 1990. “Do Security Analysts Overreact?" American Economic Review 80 (2): 52-57.

De Long, J. Bradford, Andrei Shleifer, Lawrence H. Summers, and Robert J. Waldmann. 1990. "Noise Trader Risk in Financial Markets." Journal of Political Economy 98 (4): 703-38.

Del Negro, Marco, and Stefano Eusepi. 2011. "Fitting Observed Inflation Expectations." Journal of Economic Dynamics and Control 35 (12): 2105-131.

Eisner, Robert. 1978. Factors in Business Investment. National Bureau of Economic Research.

Fazzari, Steven M., R. Glenn Hubbard, and Bruce C. Petersen. 1988. "Financing Constraints and Corporate Investment." Brookings Papers on Economic Activity 1988:141-206.

Figlewski, Stephen, and Paul Wachtel. 1981. "The Formation of Inflationary Expectations." Review of Economics and Statistics 63 (1): 1-10.

Fuhrer, Jeff. 2015. "Expectations as a Source of Macroeconomic Persistence: Evidence from Survey Expectations in Dynamic Macro Models." Working Paper no. 12-19, Federal Reserve Bank of Boston.

Fuster, Andreas, Benjamin Hebert, and David Laibson. 2012. "Natural Expectations, Macroeconomic Dynamics, and Asset Pricing." NBER Macroeconomics Annual 2011, vol. 26, ed. Daron Acemoglu and Michael Woodford, 1-48. Chicago: University of Chicago Press.

Gennaioli, Nicola, Andrei Shleifer, and Robert Vishny. 2015. "Neglected Risks: The Psychology of Financial Crises." American Economic Review 105 (5): 310-314.

Greenwood, Robin, and Samuel G. Hanson. 2015. "Waves in Ship Prices and Investment." Quarterly Journal of Economics 130 (1): 55-109.

Greenwood, Robin, and Andrei Shleifer. 2014. "Expectations of Returns and Expected Returns." Review of Financial Studies 27 (3): 714-46.

Graham, John R., and Campbell R. Harvey. 2011. "The Duke/CFO Business Outlook Survey."

Duke CFO Global Business Outlook. http:www.cfosurvey.org.

Guiso, Luigi, and Giuseppe Parigi. 1999. "Investment and Demand Uncertainty." Quarterly Journal of Economics 144 (1): 185-227.

Guiso, Luigi, Luigi Pistaferri, and Raghu Suryanarayanan. 2006. "Investment Plans." Working Paper. Einaudi Institute for Economics and Finance.

Hayashi, Fumio. 1982. "Tobin's Marginal $q$ and Average $q$ : A Neoclassical Interpretation." Econometrica 50 (1): 213-24.

Hirshleifer, David, Jun Li, and Jianfeng Yu. 2015. "Asset Pricing in Production Economies with Extrapolative Expectations." Journal of Monetary Economics 76 (2015): 87-106.

Hribar, Paul, and John McInnis. 2012. “Investor Sentiment and Analysts' Earnings Forecast Errors." Management Science 58 (2): 293-307.

Kahneman, Daniel, and Amos Tversky. 1972. "Subjective Probability: Judgment of Representativeness." Cognitive Psychology 3:430-54.

Keane, Michael P., and David E. Runkle. 1990. "Testing the Rationality of Price Forecasts: New Evidence from Panel Data." American Economic Review 80 (4): 714-35. 
1998. "Are Financial Analysts' Forecasts of Corporate Profits Rational?" Journal of Political Economy 106 (4): 768-805.

Kothari, S. P., Jonathan Lewellen, and Jerold B. Warner. 2014. "The Behavior of Aggregate Corporate Investment." MIT Sloan Research Paper no. 5112-14, Sloan School of Management, Massachusetts Institute of Technology.

Lamont, Owen A. 2000. "Investment Plans and Stock Returns." Journal of Finance 55 (6): 2719-45.

La Porta, Rafael. 1996. "Expectations and the Cross-Section of Stock Returns." Journal of Finance 51 (5): 1715-42.

Leahy, John V., and Toni M. Whited. 1996. "The Effect of Uncertainty on Investment: Some Stylized Facts." Journal of Money, Credit, and Banking 28 (1): 64-83.

Lettau, Martin, and Sydney Ludvigson. 2001. "Consumption, Aggregate Wealth, and Expected Stock Returns." Journal of Finance 56 (3): 815-49.

— 2002. "Time-Varying Risk Premia and the Cost of Capital: An Alternative Implication of the $Q$ Theory of Investment." Journal of Monetary Economics 49 (1): 31-66.

Levchenko, Andrei A., and Nitya Pandalai-Nayar. 2015. "TFP, News, and 'Sentiments': The International Transmission of Business Cycles." NBER Working Paper no. 21010, Cambridge, MA.

Lim, Terence. 2001. "Rationality and Analysts' Forecast Bias." Journal of Finance 56 (1): 369-85.

Liu, Jing, and Wei Su. 2005. "Forecasting Analysts' Forecast Errors." Working paper, University of California, Los Angeles.

Lorenzoni, Guido. 2009. "A Theory of Demand Shocks." American Economic Review 99 (5): 2050-84.

Mankiw, N. Gregory, and Ricardo Reis. 2002. "Sticky Information versus Sticky Prices: A Proposal to Replace the New Keynesian Phillips Curve." Quarterly Journal of Economics 117 (4): 1295-328.

Manski, Charles F. 2004. "Measuring Expectations." Econometrica 72 (5): 1329-76.

Monti, Francesca. 2010. "Combining Judgment and Models." Journal of Money, Credit and Banking 42 (8): 1641-62.

Morck, Randall, Andrei Shleifer, Robert W. Vishny, Matthew Shapiro, and James M. Poterba. 1990. "The Stock Market and Investment: Is the Market a Sideshow?" Brookings Papers on Economic Activity 1990:157-215.

Muth, John F. 1961. "Rational Expectations and the Theory of Price Movements." Econometrica 29 (3): 315-35.

Philippon, Thomas. 2009. "The Bond Market's q." Quarterly Journal of Economics 124 (3): 1011-56.

Piazzesi, Monika, Juliana Salomao, and Martin Schneider. 2015. "Trend and Cycle in Bond Premia." Working paper, Stanford University. http:/ / web.stanford .edu/ piazzesi/trendcycle.pdf.

Prescott, Edward. 1977. "Should Control Theory be Used for Economic Stabilization?" Journal of Monetary Economics 1977:13-38.

Sharpe, Steven A., and Gustavo A. Suarez. 2014. "The Insensitivity of Investment to Interest Rates: Evidence from a Survey of CFOs." FEDS Working Paper no 2014-02. Federal Reserve Board.

Shiller, Robert J. 1981. "Do Stock Prices Move Too Much to be Justified by Subsequent Changes in Dividends?" American Economic Review 71 (3): 421-36.

Sims, Christopher A. 2003. "Implications of Rational Inattention." Journal of Monetary Economics 50 (3): 665-90. 
2010. "Rational Inattention and Monetary Economics." Handbook of Monetary Economics 3:155-81.

Smets, Frank, Anders Warne, and Rafael Wouters. 2014. "Professional Forecasters and Real-Time Forecasting with a DSGE Model." International Journal of Forecasting 30 (4): 981-95.

Souleles, Nicholas S. 2004. “Expectations, Heterogeneous Forecast Errors, and Consumption: Micro Evidence from the Michigan Consumer Sentiment Surveys." Journal of Money, Credit and Banking 36 (1): 39-72.

Stambaugh, Robert F. 1999. "Predictive Regressions." Journal of Financial Economics 54 (3): 375-421.

Tversky, Amos, and Daniel Kahneman. 1974. “Judgment under Uncertainty: Heuristics and Biases." Science 185 (4157): 1124-31.

Universities-National Bureau Committee for Economic Research. 1960. The Quality and Economic Significance of Anticipations Data. Princeton, NJ: Princeton University Press.

Vissing-Jorgensen, Annette. 2004. "Perspectives on Behavioral Finance: Does 'Irrationality' Disappear with Wealth? Evidence from Expectations and Actions." NBER Macroeconomics Annual 2003, vol. 18, ed. Mark Gertler and Kenneth Rogoff, 139-208. Cambridge, MA: MIT Press.

Zarnowitz, Victor. 1985. "Rational Expectations and Macroeconomic Forecasts." Journal of Business and Economic Statistics 3 (4): 293-311. 